University of Louisville

ThinkIR: The University of Louisville's Institutional Repository

Electronic Theses and Dissertations

$8-2020$

\title{
A GIS-based method for archival and visualization of microstructural data from drill core samples.
}

\author{
Elliott Holmes \\ University of Louisville
}

Follow this and additional works at: https://ir.library.louisville.edu/etd

Part of the Databases and Information Systems Commons, Geology Commons, and the Geophysics and Seismology Commons

\section{Recommended Citation}

Holmes, Elliott, "A GIS-based method for archival and visualization of microstructural data from drill core samples." (2020). Electronic Theses and Dissertations. Paper 3574.

https://doi.org/10.18297/etd/3574

This Master's Thesis is brought to you for free and open access by ThinkIR: The University of Louisville's Institutional Repository. It has been accepted for inclusion in Electronic Theses and Dissertations by an authorized administrator of ThinkIR: The University of Louisville's Institutional Repository. This title appears here courtesy of the author, who has retained all other copyrights. For more information, please contact thinkir@louisville.edu. 


\title{
A GIS-BASED METHOD FOR ARCHIVAL AND VISUALIZATION OF MICROSTRUCTURAL DATA FROM DRILL CORE SAMPLES
}

\author{
By \\ Elliott Holmes \\ B.S. University of Louisville 2018
}

\begin{abstract}
A Thesis
Submitted to the Faculty of the

College of Arts and Sciences of the University of Louisville

In Partial Fulfillment of the Requirements

For the Degree of
\end{abstract}

Master of Science in

Applied Geography

Department of Geography and Geosciences

University of Louisville

Louisville, KY

August 2020 



\title{
A GIS-BASED METHOD FOR ARCHIVAL AND VISUALIZATION OF MICROSTRUCTURAL DATA FROM DRILL CORE SAMPLES
}

\author{
By \\ Elliott Holmes \\ A Thesis Approved on \\ August 11, 2020 \\ By the following Thesis Committee:
}

\begin{tabular}{c}
\hline Jafar Hadizadeh, Ph.D. \\
\hline Andrea Gaughan, Ph.D. \\
Forrest Stevens. Ph.D. \\
\hline
\end{tabular}

Aly Farag, Ph.D. 


\section{ACKNOWLEDGEMENTS}

I would first like to thank my mentors - Jafar Hadizadeh, Andrea Gaughan, Forrest

Stevens, Aly Farag, and DJ Biddle - who presented me with an exciting opportunity and unwavering support. My fellow students and department faculty were always willing to lend an ear as well and for that, I am extremely grateful. I also express gratitude for the folks at University of Louisville's Conn Center, Clinical Translational Research Center; and the University of Kentucky's Mineral Resources Department that kindly offered their instruments and expertise. I thank the National Science Foundation for providing the funding and SAFOD core samples for this research. My wife, Alex, has supported my academic and professional endeavors unconditionally. When needing encouragement, or maybe just a home-cooked meal, I was fortunate to have an incredible support system provided by my parents, Steve and Michele. An exhaustive account of those I would like to acknowledge deserves a thesis in its own right, but I am thankful to many nonetheless. 


\section{ABSTRACT \\ A GIS-BASED METHOD FOR ARCHIVAL AND VISUALIZATION OF MICROSTRUCTURAL DATA FROM DRILL CORE SAMPLES \\ Elliott Holmes}

August 5, 2020

Core samples obtained from scientific drilling could provide large volumes of direct microstructural and compositional data, but generating results via the traditional treatment of such data is often time-consuming and inefficient. Unifying microstructural data within a spatially referenced Geographic Information System (GIS) environment provides an opportunity to readily locate, visualize, correlate, and explore the available microstructural data. Using 26 core billet samples from the San Andreas Fault Observatory at Depth (SAFOD), this study developed procedures for: 1. A GIS-based approach for spatially referenced visualization and storage of microstructural data from drill core billet samples; and 2. Producing 3D models of sample billets and thin section positions within each billet, which serve as a digital record after irreversible material loss and fragmentation of physical billets. This approach permits spatial registration of 2D thin section 'base maps' within the core sample billets, where each billet is represented by 3D solid surface (produced via SFM photogrammetry) and internal structure models (acquired with micro-CT scans) created prior to sectioning. The spatial positions of the base maps were established within locally defined coordinate systems in each core billet's solid surface model. The GIS database structure provided interactive linkage to 
the results of various analyses performed throughout the map at a wide range of scales (e.g. SEM and CL images as well as text and numerical data) within each thin section. The viability of the proposed framework was demonstrated via display of integrated microstructural data, creation of vector point information associated with features of interest in CL imagery, and development of a model for extraction and unsupervised classification of a multi-generation calcite vein network from the CL imagery. The results indicate that a GIS can facilitate the spatial treatment of 2D and 3D data even at centimeter to nanometer scales, building upon existing work which is predominantly limited to the 2D space of single thin sections. Conversely, the research effort also revealed several challenges, particularly involving intensive 3D representations and complex matrix transformations required to create geographically translated forms of the within-billet coordinate systems, which are suggested for consideration in future studies. 


\section{TABLE OF CONTENTS}

\section{PAGE}

ACKNOWLEDGEMENTS .........................................................

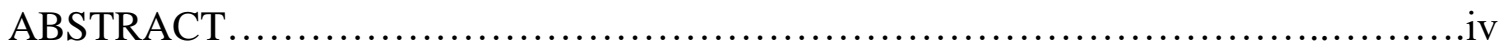

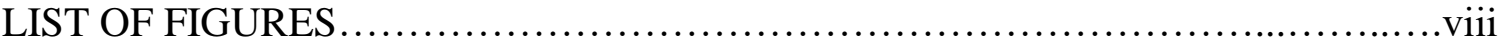

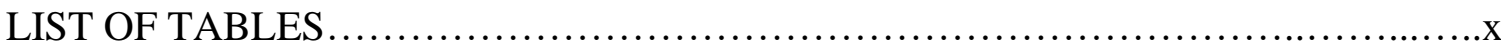

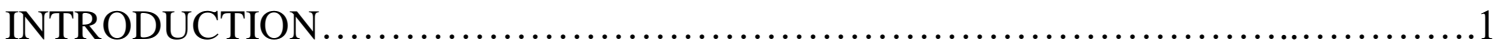

Objectives and Research Questions............................................

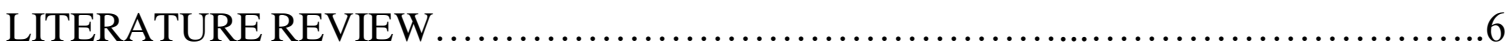

Scientific Drilling for Solid Earth Research...................................6

Traditional Analyses in Structural Geology .....................................

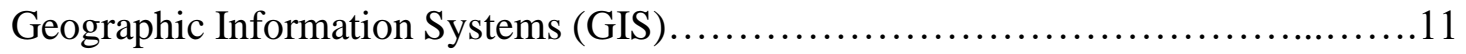

Remote Sensing ...............................................................

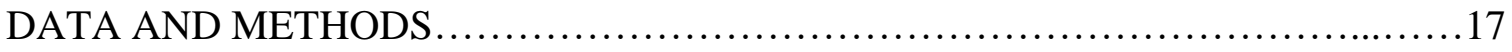

The Core Samples.......................................................... 19

3D Billet Models............................................................19

Data from Petrographic Thin Sections....................................... 24

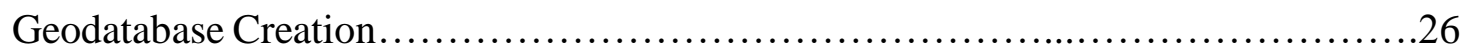

Cathodoluminescence (CL) Image Analysis.................................29

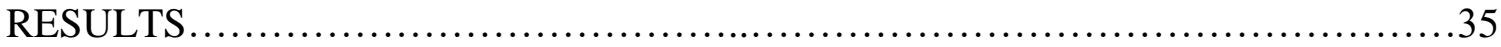

CL Image Analysis..................................................... 39 
Digital Modelling to Preserve Physical Records: Successes and Challenges.

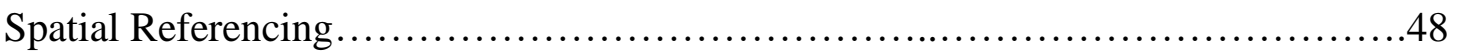

Remote Sensing Techniques Applied to CL Imagery..............................51

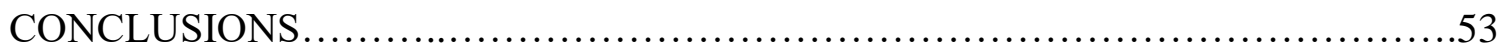

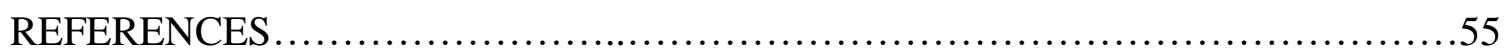

APPENDIX A: Instruments used for Data Collection................................63

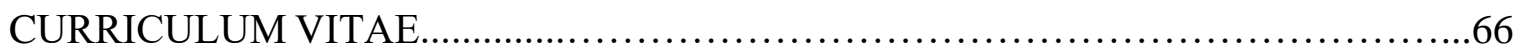




\section{LIST OF FIGURES}

PAGE

Figure 1. Overview of the research objectives and deliverables.......................

Figure 2. Diagram of workflow for in situ data collection and GIS-based integration......18

Figure 3. Overview of SAFOD core lithology and billet samples....................19

Figure 4. Billet photography environment for SFM photogrammetry $\ldots \ldots \ldots \ldots \ldots \ldots \ldots .21$

Figure 5. Image processing procedures to generate 3D billet models..................22

Figure 6. Examples of 3D billet models ......................................23

Figure 7. Traditional microstructural data sources...............................25

Figure 8. CL image containing two apparent calcite vein generations and areas of interest

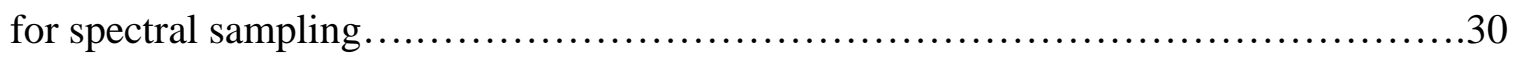

Figure 9. The CIE 1931 color standard used for spectral wavelength acquisition from RGB image pixels............................................................... 31

Figure 10. Intermediate data from the CL image classification procedure...............32

Figure 11. Model for extraction and classification of calcite veins in CL imagery.........34

Figure 12. Illustration of GIS-based visualization and navigation of microstructural

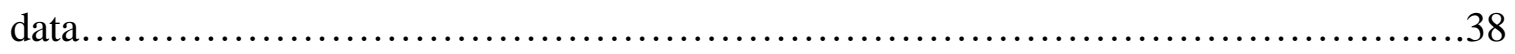

Figure 13. Map view of CL image and spectral data points.........................40

Figure 14. Output from unsupervised classification of two calcite vein generations.......42

Figure 15. Examples of processed 3D solid surface models.........................45 
Figure 16. SAFOD core orientation diagram suggesting information for spatial referencing

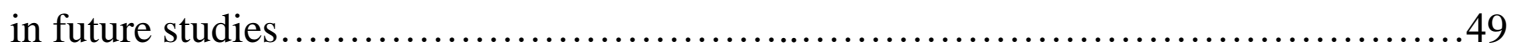

Figure 17. Suggested framework for more precise thin section orientation...............50 


\section{LIST OF TABLES}

PAGE

Table 1. Accuracy assessment results for the classified CL image output...............43 


\section{INTRODUCTION}

In recent decades, scientific drilling activities aimed at solid earth research such as tectonic deformation, heat flow, and earthquakes have been on the increase. By examining geophysical logs recorded during drilling and cored rock exhumed from the boreholes thereafter, the scientific community has gained new insight on Earth's subsurface processes and structures. Active fault zone drilling has informed critical advancements in our understanding of fault system dynamics and composition, and how those factors then coalesce to influence seismic hazards experienced by humans at the surface. Geophysical instrumentation and core samples thus provide a crucial, "deep" perspective on fault systems that is not otherwise attainable solely through surface observations or historical analysis of seismic events (Hofmann et al. 2019; Ma et al. 2006).

Structural geologists often utilize traditional analytical techniques such as X-ray diffraction (XRD), cathodoluminescence (CL or SEM-CL), electron backscatter diffraction (EBSD), and optical and electron microscope imaging to gather data from drill cores (Willard and McWilliams 1969). Although these established techniques generate large volumes of reliable measurements, deriving results via the traditional, piecemeal treatment of the data is often a time-consuming and inefficient process. Without a method for integrating various $2 \mathrm{D}$ and $3 \mathrm{D}$ products the ability to see and quantify spatial relationships between sample drill core billets, including the multi-modal and -scalar data from petrographic thin sections within them, is potentially limited (Tickoff et al. 2018). 
Unifying core-based data in a Geographic Information System (GIS) allows researchers to locate, visualize, correlate, and explore microstructural characteristics in a streamlined interface. While GIS software is mostly utilized in georeferenced-based analyses, it provides robust database management and analysis structures that facilitate spatially explicit treatment of data regardless of its type or scale (Rose 2012). As such, in situ microstructural data collected at the nanometer-millimeter scale also fundamentally contain spatial information that can be efficiently archived and analyzed within a geospatial framework. The time needed for spatial inspection and analyses of data collected via traditional analytical techniques can potentially be reduced as a result. Recognition of this fact has allowed structural geologists to maximize the potential of their data and address interdisciplinary questions that were previously challenging.

Building on previous innovative work in 'micro-GIS', the methods described here leverage GIS tools to integrate various multi-dimensional data layers, both numerical and visual, to produce accurately referenced results and digital models of sample billets extracted from drill cores. Utilizing ESRI's ArcGIS software suite (ESRI 2020), my study establishes micro-GIS procedures and tests the data management process with core samples from the San Andreas Fault Observatory at Depth (SAFOD). Core samples were obtained through an NSF grant (\#1800933), with the larger project objective studying microstructural deformation in 26 billets sampled from $\sim 40$ meters of core extracted during the SAFOD Phase III drilling.

The established imaging techniques of structure from motion (SFM) photogrammetry and computed tomography (CT) were first used to create 3D digital models of the stillintact billets' solid surface and internal structure, establishing crucial arbitrary $x y z$ 
coordinate systems within each digital billet. In addition, the models serve as a record of billet state prior to sectioning and physical degradation from analytical procedures. The petrographic thin sections were subjected to optical light, SEM, and SEM-CL imaging following extraction from the sample billets. Tabulated XRD data were obtained (postsectioning) from powdered billet fragments.

This thesis first includes a review of relevant threads within the diverse, multidisciplinary literature that characterizes the scope of the study. Upon establishing a contextual background on traditional micro-analytical techniques and implementations of geospatial tools, the literature review shifts to emergent perspectives on the need for more integrative and spatialized geological research. A brief overview of the SAFOD core lithology and the locations of sample billets used in the study is then provided, followed by an account of the various microstructural data collected from petrographic thin sections extracted from within the billets.

The reader should at this point note that, while geospatial software provide a robust suite of tools for database management and integration of 3D models and 2D thin sectionbased data, ArcGIS was complemented with several other specialized programs designed for various initial data collection and pre-processing tasks. Primary analytical procedures and their associated instrumentation and/or software are detailed in the text resuming. This includes the steps in image acquisition and processing for 3D model construction, spatial registration of 3D models with associated 2D thin section-based data, and microscale database management under the GIS framework. The results of a GIS-based demonstration, focused on image classification and mapping of the spatial distribution of microstructural characteristics obtained from cathodoluminescence (CL) image analysis, 
are then provided in the final component. An overview of the study objectives can be seen in Figure 1.

\section{Framework for Collection, Management, and Spatial Analysis of SAFOD Project Data}

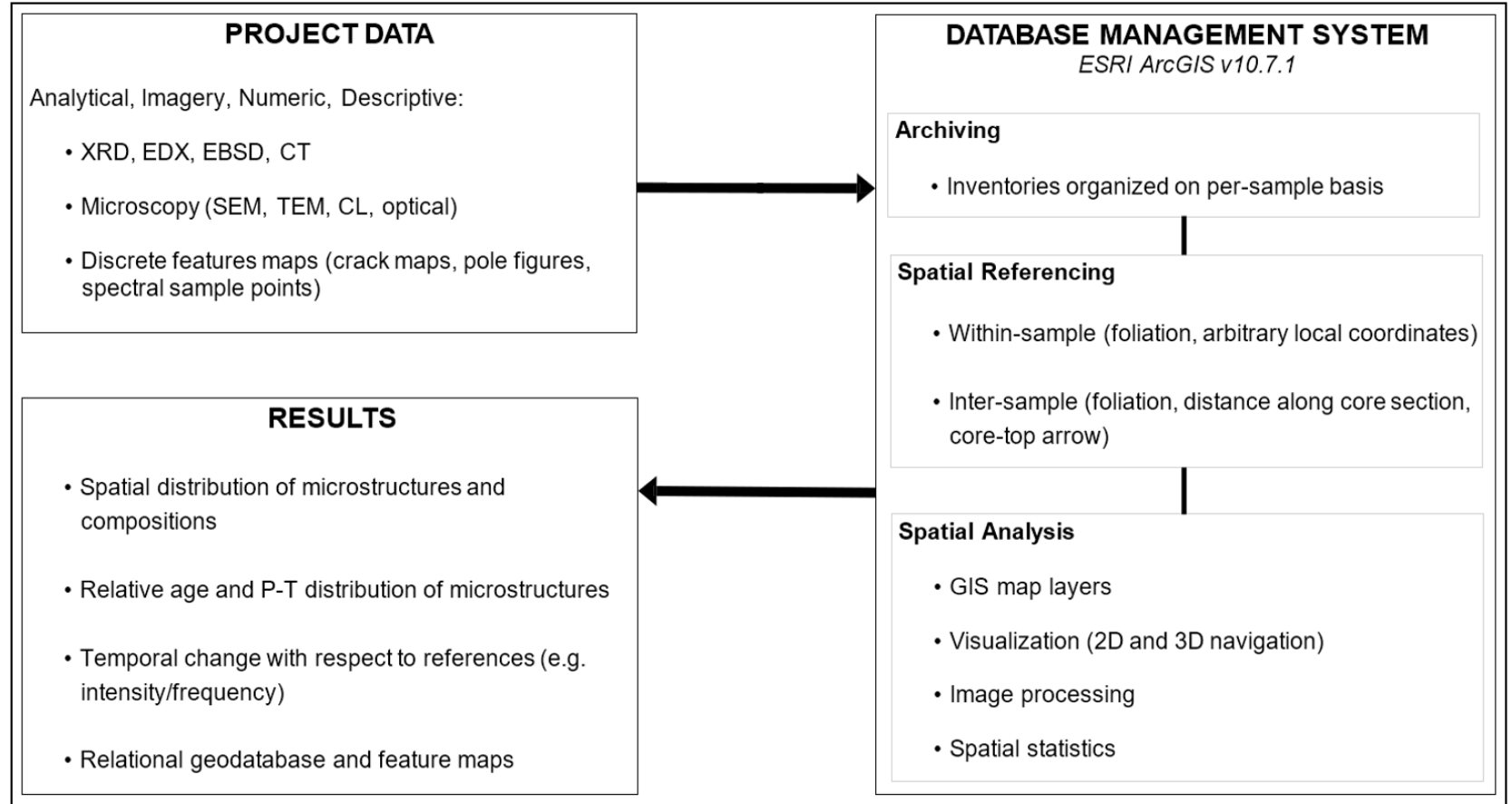

Figure 1. Overview of the research effort including project data collection, GIS database management, spatial analyses, and results. 


\section{Research Objectives}

1. Develop a GIS-based method for spatially referenced visualization and storage of microstructural data from drill core billet samples;

2. Produce 3D models of sample billets and thin section positions within each billet, which serve as a digital record after irreversible material loss and fragmentation of the physical billets;

3. Demonstrate viability of the micro-GIS framework via: a) geodatabase integration and display of multi-modal 2D, 3D, and tabulated microstructural data; b) digitization of vector point information associated with features of interest in CL imagery; and c) creation of a semi-automated model for extraction, followed by unsupervised classification and segmentation, of a multi-generation calcite vein network from CL imagery.

\section{Research Questions}

1. How can a geospatial framework be leveraged to enhance efforts in archival, analysis, and modelling of micro-scale spatial data collected via traditional analytical techniques in structural geology?

2. Does a micro-GIS support effective procedures for spatial digitization of ancillary vector data, image processing tasks such as feature extraction and classification, and quantitative assessment of CL image data and derived outputs? 


\section{LITERATURE REVIEW}

\section{$\underline{\text { Scientific Drilling for Solid Earth Research }}$}

The data returned from borehole logs and direct analyses of cores extracted, in conjunction with computational and analytical advances, have contributed to a wealth of new knowledge of the physical and chemical processes that govern faulting and resulting seismic activity (Hofmann et al. 2019; Ma et al. 2006; Reches and Ito 2007; and Tobin et al. 2007). Several successful drilling projects have been completed in the last 20 years, many of which are supported by the International Continental Scientific Drilling Program (ICDP). The following list, though not exhaustive, identifies several projects that have been completed in recent decades:

1. Following the deadly 1995 earthquake that struck the city of Kobe, a series of boreholes were drilled into the Nojima Fault in Japan.

2. The Taiwan Chelungpu-Fault Drilling Project (TCDP) saw two boreholes completed in 2005, complementing the country's dense array of seismic monitoring instrumentation.

3. Korea completed drilling of two boreholes into the Yangsan fault between 2012 and 2016 at the Pohang Basin Enhanced Geothermal System (EGS) site.

4. The ICDP has additionally supported notable projects - among many others - such as the Deep Geodynamic Laboratory (DGLab) in Greece, the Multidisciplinary Observatory and Laboratory of Experiments (MOLE) drilling project in Italy, and 
the San Andreas Fault Observatory at Depth (SAFOD) in central California (ICDP 2020).

\section{$\underline{\text { Traditional Analyses in Structural Geology }}$}

Established analytical techniques such as optical and electron microscope imaging, Xray powder diffraction, electron backscatter diffraction, energy-dispersive X-rays, and cathodoluminescence have been utilized for decades to gather large volumes data from geological specimen. In many applications, a combination of several approaches is adopted. An account of the full array of data collection methods employed in solid earth research is not attainable within the scope of this thesis, but the following section does provide a review of key contextual information and approaches regarding the data types that were collected and integrated during the SAFOD project.

\section{Optical and Scanning Electron Microscopy (SEM)}

Optical microscope imaging, also commonly referred to as light microscopy, is widely adopted for specimen imaging in a variety of scientific disciplines. Optical microscopes operate by focusing a beam of light on or through and object, producing an enlarged image of the specimen via a series of convex lenses. The images can be directly viewed through the microscope, but research typically requires image capture via a digital CCD camera or other more specialized sensors. Optical microscopy offers a high degree of flexibility for different applications; the illumination source, color filters, light polarization, and lens magnification can be manipulated to suit various investigative requirements (Murphy 2002). 
Scanning electron microscopy (SEM) is another highly adaptable imaging technique that has seen widespread use across the physical sciences. By scanning the surface of a specimen with a focused electron beam, SEMs produced a gridded raster image that often achieve sub-nanometer spatial resolutions. Similar to optical light microscopes, the electrons can be transmitted through the sample or reflected from its surface. Depending on the type of material, emission, and detector used, atoms emit various signals that can be measured and subjected to quantitative analyses (Lin and Cerato 2014; Reed 2005; Smith and Oatley 1955).

SEM and optical microscopy are also firmly established in the realm of earth systems science, structural geology, and geomorphology (Davidson and Lofgren 1991; Trimby and Prior 1999). Common geological applications of these technique include studies of micro-structural deformation, temporal evolution of physio-chemical conditions, and mineralogical composition of material contained withing petrographic thin sections (Hadizadeh et al. 2012; Hadizadeh and Boyle 2018; Holdsworth et al. 2011; Janssen et al. 2011; Solum et al. 2006; Willard and McWilliams 1969; Zoback, Hickman, and Ellsworth 2011).

\section{Cathodoluminescence (CL) Microscopy}

Luminescence, a form of cold-body radiation, is the spontaneous emission of light from a substance not produced by heat. When bombarded with a high-voltage electron beam, luminescent minerals emit light at various wavelengths depending on their composition. CL detectors attached to scanning electron microscopes (SEM), field 
emission microscopes (FEM), and electron microprobes (EPMA) can accurately measure these emissions and generate high-resolution imagery (Gotze 2002).

CL is commonly applied in solid earth science for investigations of growth and dissolution features in ore minerals, growth structures in fossils, cementation and diagenesis processes in sedimentary rocks, and the chemical and mechanical conditions of mineralized systems as they evolve through time (Habermann 2002). The latter is the focus of the GIS-based demonstration discussed later, as the fault gouge at the SAFOD is characterized by a host of deformation microstructures including complex, multigeneration networks of calcite and quartz veins. Calcite veins are the cemented remnants of fluids introduced through repeated fracture-seal episodes within the host rock, each episode producing a new generation due to varying levels of trace impurities in the source fluid (Verheart et al. 2004). With well-established spectral proxies, CL allows identification of vein generations and the relative time, depth, and fluid conditions in which they formed (Barnaby and Rimstidt 1989; Budd, Hammes, and Ward 2000; Cazenave, Chapoulie, and Villeneuve 2003; Fairchild 1983; Hadizadeh and Boyle 2018).

\section{X-Ray Diffraction (XRD)}

X-ray powder diffraction, also known as 'XRD', is an analytical technique for measuring the atomic structure of crystalline materials. In this sense, a crystal can be considered as a homogeneous ensemble of molecules that correspond to a single mineral phase. At this scale, the molecular structure is often described as a crystal "lattice". Based on atomic composition, molecular structure, and stress orientation, lattices diffract X-ray light in different but distinct ways. Researchers working with poly-crystalline 
substances must often reduce their sample to a fine powder to reduce noise from mixedlattice signals; this is the approach adopted in this research (Cullity 1956; Robinson and Tweet 1992; Whittig and Allardice 1986).

Once a small quantity of powdered sample is staged, the scanner simultaneously manipulates its $\mathrm{x}$-ray emitter and detector to measure diffraction along a specified range of angles ( 1 and 90 degrees) and number of scan iterations. XRD analysis produces a tabulated dataset of the material's monochromatic x-ray reflectance at each angle in the specified interval. Producing a histogram from these data reveals peaks and troughs in the sample's spectral profile, which reveals information about crystal lattice composition and orientation and essentially provides a 'fingerprint' associated with the presence or lack of known material phases. In structural geology, XRD is commonly applied in tandem with other techniques to characterize the minerology, structure, and stresses of materials at the atomic level (Hupp and Donovan 2018; Lee and Xu 2017; Tavakoli 2020; Zhou et al. 2018). Spatially, the results of XRD are tied to the entire sample from which the powder was obtained.

\section{Computed X-Ray Tomography (CT)}

CT scans are a non-destructive 3D imaging technique with a range of applications in core-based research, along with many other subfields in geology and bio-medicine. Like XRD, CT data are derived from a sample's reflectance of monochromatic x-ray emissions. However, CT differs in that it generates 3D visualizations of the sample's internal structure. CT imaging involves a stepwise radial scanning process that measures the attenuation of $\mathrm{x}$-ray signals throughout the object, generating a series of one or more 
2D cross sections which are perpendicular to the axis of rotation. By exploiting differences in the degree of signal attenuation, researchers gain spatial insight on the composition, density, and energy content of various materials (Coenen et al. 2004; Mees et al. 2003; Renter 1989; Sim et al. 2020; Wu and Hu 2019).

\section{Emergent Perspectives}

A case-study in Ireland (Whitmeyer et al. 2010) states that geoscience students reported difficulty making real spatial associations while interpreting traditional geological maps and compartmentalized data sources. Conversely, the authors found that incorporation of geospatial tools and visualization techniques enhanced efforts to display, analyze, and thus comprehend geological field data. In recognition of the database management and visual representation challenges with which geology is confronted, some studies publications have urged the community to explore more integrated and spatialized techniques (Chan, Peters, and Tickoff 2016; Tickoff et al. 2019).

\section{Geographic Information Systems (GIS)}

Geographic Information Systems (GIS) have traditionally been used to manage data that span scales of meters to kilometers, incorporating images captured via airborne sensors or point information collected with GPS-enabled devices. Local- to global-scale studies across multiple disciplines including anthropogenic climate change, socioeconomic conditions, crime distribution, transportation networks, or ecological systems dynamics (Edward and Biddle 2017; Gaughan et al. 2013; Malczewski 2004; Zhang and Peterson 2007). One unifying aspect of the majority sample is the relevance of spatial 
context; the coordinate space that defines the study area is often inseparable from the generated results. This holds true at the micro-scale as well, opening the door for structural geologists to utilize GIS database management structures and analytical tools to see and quantify spatial data in new ways.

Previous work demonstrates the efficacy of GIS for integration and analysis of 2D microscopic image data (Barraud 2006; Berrezueta et al. 2017; Haaland et al. 2017; Hassanpour 2012; Lezzerini et al. 2016; Ortolano 2018; Tarquini and Favalli 2010; Wohlmutter 2017; Yingkui, Onash, and Guo 2008), while others have offered methods for orientation of petrographic thin sections to real-world geographic coordinates (Chan et al. 2016; Tickoff et al. 2018; Walker et al. 2019). The work of Linzmeier et al. (2018) is particularly informative, creating a framework for spatial registration of multisource microstructural data from within a single thin section in arbitrary, twodimensional space. By using GIS software to integrate raster images from optical and electron microscopes, along with vector point data from secondary ion mass spectrometry (SIMS) and electron probe microanalysis (EPMA), the authors mapped the distribution of structural and chemical characteristics across various crystal grains (Linzmeier et al. 2018). Another study that my method expands upon is that of Basil Tikoff et al. (2019). They propose a robust framework for defining the orientation of thin sections relative to sampled billets and the entire drill core, providing a tractable spatial registration method for both local and geographic coordinate systems. 


\section{$\underline{\text { Remote Sensing }}$}

\section{Structure from Motion (SFM) Photogrammetry}

Structure from Motion (SFM) is a low-cost and automated 3D modelling approach that is based on the aggregation of multiple $2 \mathrm{D}$ images from varying perspectives of an object or terrain. In many cases, standard digital camera images are of adequate quality for SFM reconstruction, though the approach requires careful determination of the appropriate image offset and overlap to ensure continuous coverage of the desired area. Shared pixels ('tie points') are first identified from overlapping image pairs via an iterative non-linear least-squares minimization process, enabling estimation of the camera perspectives. The complete set of image tie points form a cloud of discrete point locations with associated color data, which ultimately inform the final model by serving as the vertices from which triangular faces are interpolated. The SFM output can then be considered as a multi-resolution 'solid surface model' consisting of a 3D object mesh bound by a photo-realistic image texture (Hartley and Zisserman 2004; Westoby et al. 2012).

Many successful demonstrations of 3D reconstruction of air- and space-borne imagery have established the viability of this technique for a multitude of approaches in the realm 'traditional' remote sensing (Lucieer, Jong, and Turner 2014; Wallace et al. 2016). However, micro-scale usage of the technique is not absent in the geoscience literature. A 2017 study of small-scale soil erosion concluded that lab-based SFM techniques produced reliable topographical data sets for accurate modeling of micro-scale surfaces and change detection, indicating that $3 \mathrm{D}$ billet modeling is a viable application of photogrammetric techniques (Balaguer-Puig et al. 2017). 


\section{Image Classification}

One of the more common objectives in remote sensing is to extract meaningful information from raw spectral image data (Jensen 2015). Remote sensing classification is a discrete approach to doing this, providing a method to categorize individual pixel values into information classes representative of the image surface (Cheng, Han, and $\mathrm{Lu}$ 2017). From a broad perspective, image classification can be distilled into two distinct families: supervised and unsupervised. Supervised approaches require model training data and user intervention, but can often be the most robust method depending on the research question and model used (Maggiori et al. 2016; Maxwell, Warner, and Fang 2018; Pal 2005). On the other hand, unsupervised classification requires no user intervention and is typically performed via a pixel-wise statistical clustering based on spectral values alone (Mather 2004; Zhao and Qian 2004).

This portion of the literature review narrows its focus upon the Iterative SelfOrganizing Data Analysis Technique (ISODATA) unsupervised classification (Ball and Hall 1965), which was utilized in my study on a demonstrative and exploratory basis and not in refute of more advanced approaches that may be better suited for classification of microstructural image data. ISODATA's algorithm performs statistical clustering via an iterative cluster merging and splitting procedure. Based on user-defined thresholds, clusters are split if their values surpass a given standard deviation or merged if their mean center distances fall within the specified range until the specified number of iterations is performed (Memarsadeghi et al. 2007).

The ISODATA output is a new raster image where each pixel is categorized into one of $n$-number of spectral clusters (if 10 clusters are specified at the outset, output pixel 
values would contain whole numbers ranging from 1-10). Because the algorithm operates via pixel-wise statistical grouping that doesn't consider image context, the initial spectral clusters do not correspond directly to meaningful information classes (i.e. forested lands, water bodies, built-up environment, or in the case of this study, microscopic calcite structures). As a result, multiple spectral clusters may actually correspond to a single information class; in other scenarios, single clusters are split among two or more information classes. To obtain the final classified product, the spectral clusters are manually combined, split, and symbolized in accordance with the desired information classes using the researcher's subject matter expertise.

This study implements ISODATA for classifying calcite vein generations within microscopic cathodoluminescence (CL) imagery. Because each generation contains a unique profile of trace impurities from the source fluid, the spectral properties vary between calcite formed at different times and physio-chemical conditions (for additional information, see Cathodoluminescence Microscopy). The unsupervised algorithm exploits the variation in the image data and assigns pixels into statistical clusters that share similar spectral characteristics. The spectral clusters may then be merged into meaningful information classes (i.e. Calcite generation $1,2, \ldots n$ ).

Calcite classification is useful in geological research because the vein generations serve as proxies for the relative age, depth, fluid source, and evolution of mineralized systems through time. By deriving discrete features from the continuous CL image data, those proxies and any other desired information may be attributed to a single entity representing a given vein generation. The classified calcite veins also provide an 
opportunity for areal measurements, determining stress orientations, or other vectorbased spatial analyses. 


\section{DATA AND METHODS}

The set of steps outlined below include in-depth descriptions of: 1) 3D modelling of the SAFOD billet samples; 2) establishing local coordinate systems to facilitate spatial treatment of data in a micro-GIS; 3 ) the components of database creation and multimodal data integration; and 4) the demonstration of CL image analysis, extracting features of interest, and performing a basic image classification using geospatial tools (Figure 2). 


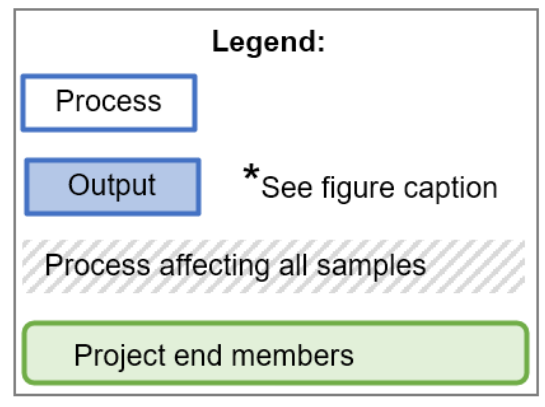

\section{Core billet samples}

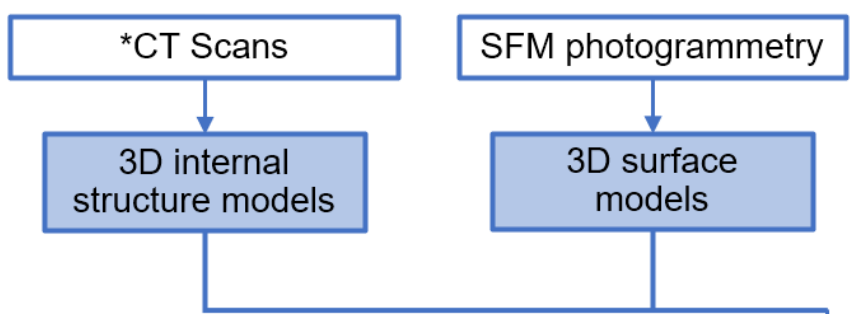

Thin section extraction from billets

Thin section samples
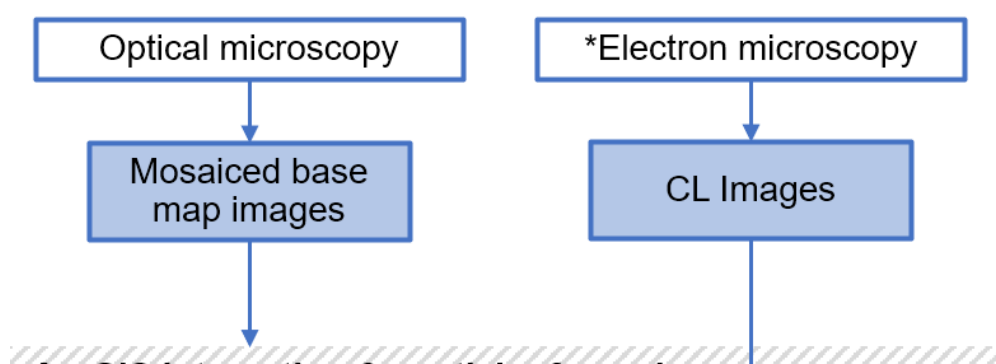

*Billet x-ray diffraction

ArcGIS integration \& spatial referencing

CL Images

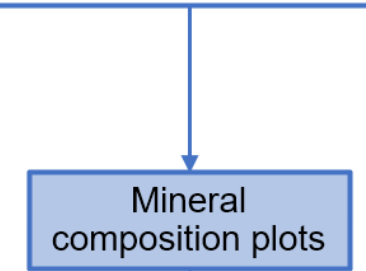

\section{Micro-GIS \\ Demonstration}

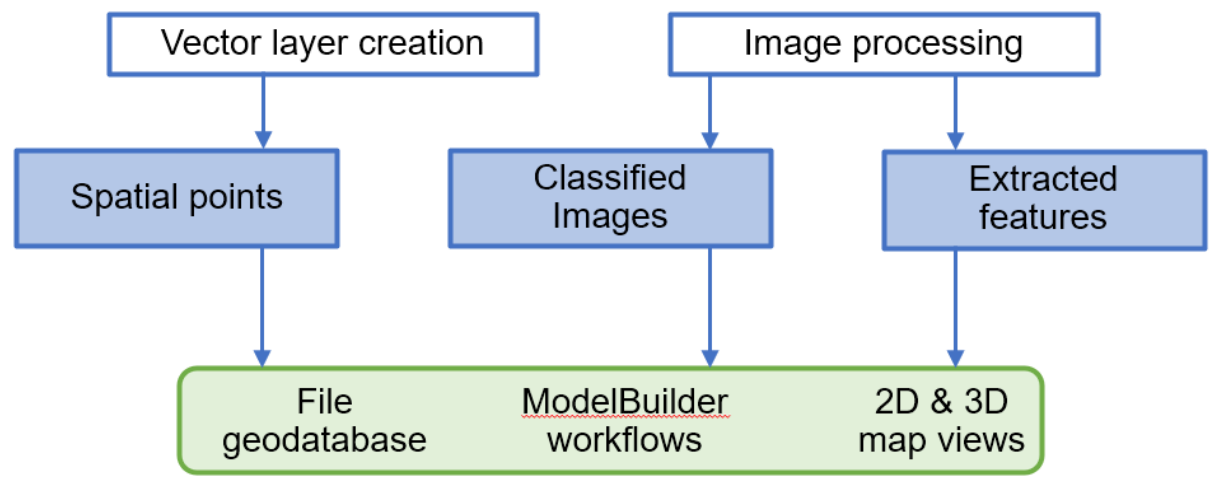

Figure 2. Workflow diagram of in situ data collection, processes, and resulting outputs under a GIS-based framework. Starred items indicate procedures carried out by others. CT scans were conducted by Huaiyu Zheng and derived outputs were produced by Aryan Ghazipour and Grace Embree. X-ray diffraction raw data were collected personally, then composition plots were created by Jafar Hadizadeh. Electron microscopy was conducted by Alan Boyle. 


\section{The Core Samples}

The method for spatialized archival of core-based data in a micro-GIS environment is applied with 26 billets from the San Andreas Fault Observatory at Depth (SAFOD), which were sampled from select areas in an approximately $40 \mathrm{~m}$ core length (Figure $3 \mathrm{a}$ ). The SAFOD core consists of 3 segments - Hole E, Hole G (Runs 1-3), and Hole G (Runs 4-6) - which are subdivided into runs, and further still into sections. Sample nomenclature in this paper reflects these designations; for example, a billet extracted from Hole E, Run 1, Section 1 (Figure 3b) will be referred to as sample 'E11'.

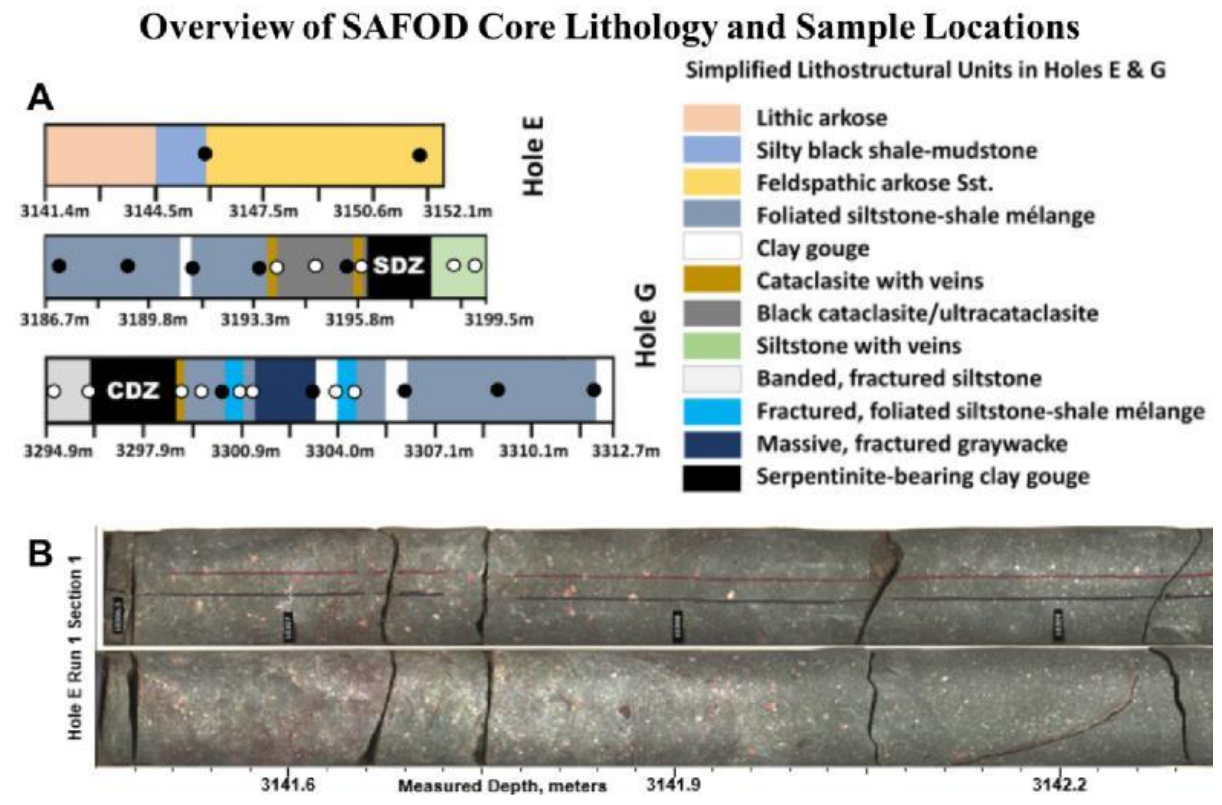

Figure 3. A) General lithological characteristics of SAFOD core sections with a legend for units (measured depth-MD-meters). Black and white circles represent the distribution of sample billets. B) Color photo of Hole E, Run 1, Section 1 including red \& black core orientation lines. Core distance markers modified after Bradbury (2011). Image of core section E11 from Earthscope (2007).

\section{$\underline{\text { 3D Billet Models }}$}

Two types of 3D digital models were produced for each billet prior to physical sectioning: Solid surface models were derived from digital camera images, and internal structural models 
were generated from micro-CT scan data. Both models serve a dual purpose: to define a local coordinate system within each billet and to retain visual or structural information of the billet's intact state. The following portion of the paper reviews the procedures for obtaining these models and then preparing them for incorporation into the GIS database.

\section{Solid Surface Models}

To retain an accurate visual representation of the billet, 3D solid surface models were generated for each billet prior to physical sectioning. These models preserve the detailed surface morphology and spatial reference annotations, which are lost upon physical sectioning due to irreversible billet fragmentation and material loss. Each physical billet was marked with a core- top arrow, a $2 \mathrm{~cm}$ scale-bar, and proposed sectioning lines. The core-top arrow is included so that the up-borehole direction is easily identifiable in the digital billet model, setting the initial stage for further calibration of billet position. The core orientation lines then allow the rotational position of billets to be established with respect to the core axis. The sectioning lines serve multiple purposes; they provide a visual indicator of where to cut the physical billet when preparing petrographic thin sections, but also indicate where to virtually cut the 3D billet model in order to carry out spatial archival of thin section-based data located within the billet. Lastly, the $2 \mathrm{~cm}$ scale bar is used to calibrate absolute map units in the processed billet models.

A Canon PowerShot G1X Mark II digital camera was used for billet imaging. Accurate image reconstruction required carefully controlled camera settings and lighting environment. The camera was placed in aperture priority (AV) mode, which adjusts the shutter speed based on the selected aperture size. In this case, a wide aperture setting of 
F16 allowed the entire image frame to be in focus. A low ISO setting of 200 reduced the shutter speed and maximized the signal-to-noise ratio. In turn, the potential for distinct features (i.e. prominent grains and fractures) to exhibit spectral variability from one image to the next is minimized. In combination with a stabilizing tripod, a 2-second image capture timer was applied to avoid blur from camera vibrations.

Consistent billet illumination was established with a light diffusion tent and four adjustable LED lights placed outside (Figure 4a). The LEDs and camera tripod were then fixed in place to avoid movement throughout the imaging process. Once the environment and camera parameters were established, images of each entire billet were captured with consistent overlap. This step was performed by placing the billets on a rotating pedestal and capturing images at each of the 13.3-degree intervals marked around the perimeter of the pedestal. The adjustable camera tripod was then used to repeat this process at consistent nadir, high, and low perspectives. To minimize visual obstruction in lowperspective images, billets were placed on a pronged sample mount (Figure 4b).

Photography Environment for SAFOD Sample Billets

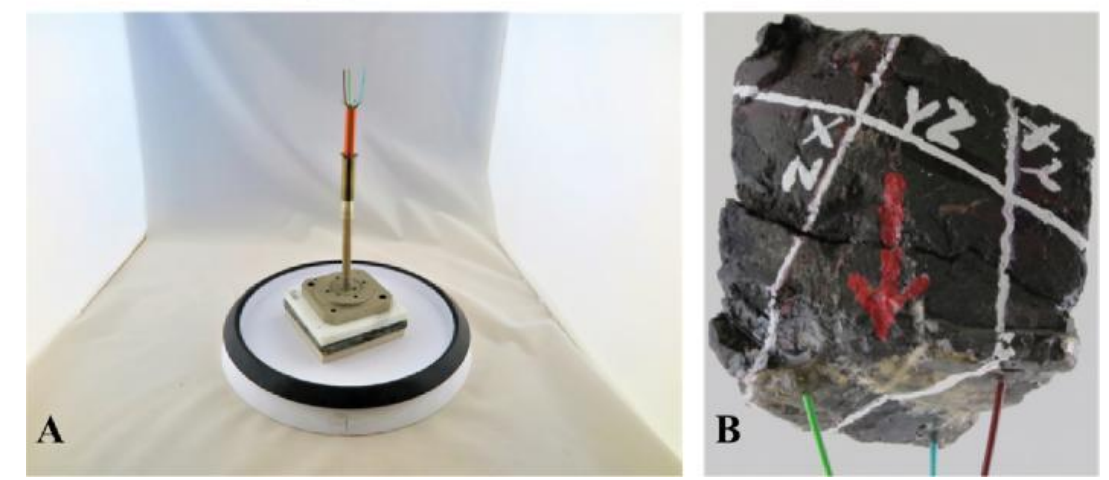

Figure 4. A) Desktop light-diffusing tent and rotating, pronged sample mount for billet photography. B) Example of low-perspective image from billet G56, including the core-top arrow and proposed sectioning lines.

The billet models were then reconstructed via SFM using Agisoft Metashape Professional (Agisoft 2018) photogrammetry software. The software first generated a 
cloud of image tie points and estimated camera positions (Figure 5a-b). Visual diagnostics of the initial point cloud and confirmation that all images successfully aligned determined if the tie point data were sufficient for densification (Figure 5c). The final solid surface models (Figure 5d) were obtained from the dense point clouds by generating a 'mesh', or 3D volume bound by triangular faces in an arbitrary local coordinate system. Agisoft's 'build texture' function then determined how the color information from the input images should be mapped to the faces of the mesh. Completed models were exported as COLLADA (.dae) files, which are readily accepted into ArcGIS.

\section{Image Processing Procedure for Billet Solid Surface Models}

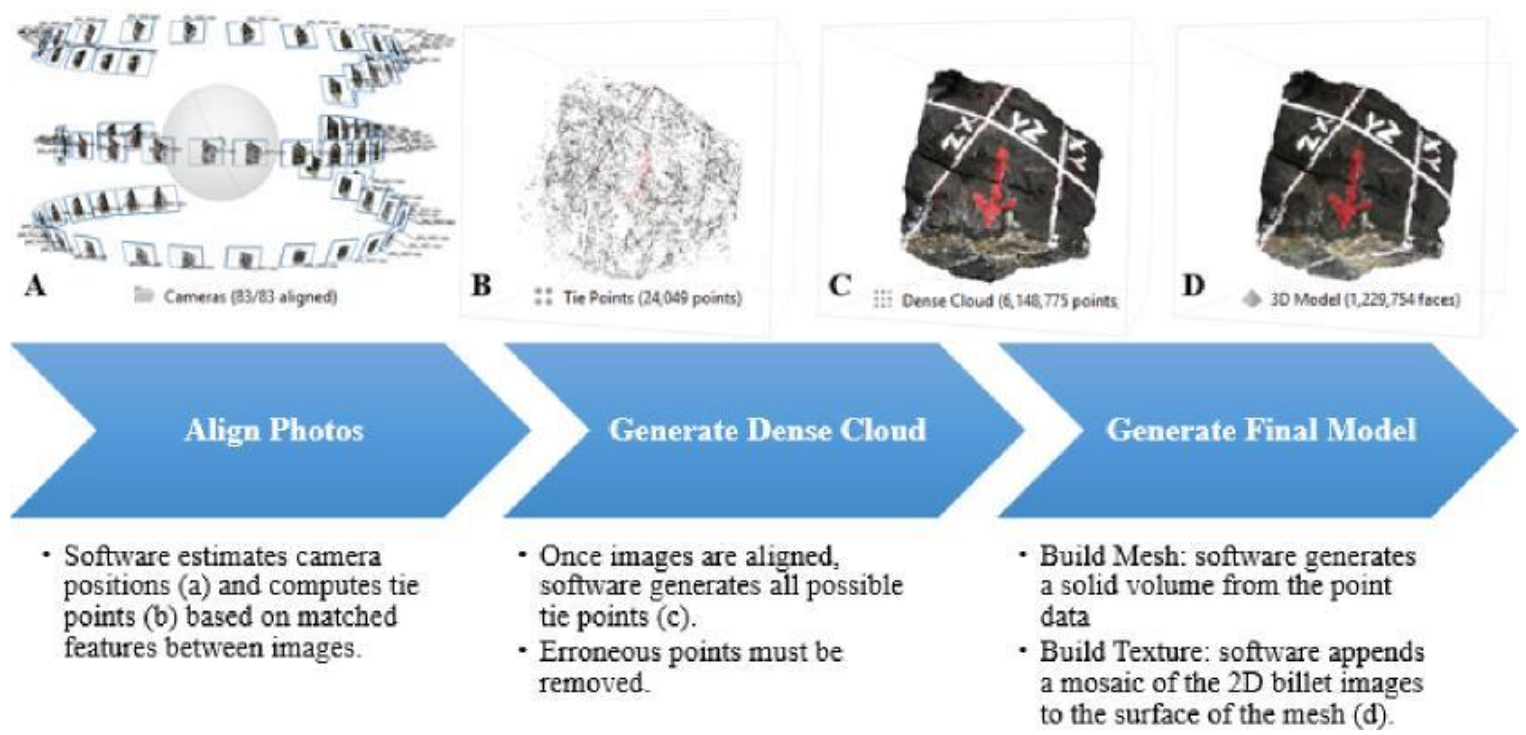

Figure 5. Procedure for processing 2D images to generate 3D billet models depicting: A) camera positions; B) initial tie points; C) dense tie points cloud; and D) processed 3D billet model.

\section{Internal Structure Models}

The internal structure models were derived from computerized X-ray tomography (CT-scan) image data consisting of a 3D stack of virtual slices throughout each billet (Figure 6b). These models provided a digital record of internal structure after the physical billets were sectioned. In addition, they offered insight on billet topology and 
allowed identification of internal features for spatial registration of 2D thin section-based data within the local $x y z$ coordinates of respective billet models. The sectioning lines were made visible in the CT-scans by placing elastic bands along the sectioning lines (shown as black lines, Figure 6a).

The 3Dslicer software (Fedorov et al. 2012; Slicer 2018) allowed entire CT data sets to be viewed and analyzed as 3D models, but ArcGIS does not provide native support for giga-voxel features. In compromise, virtual slices along the billets' section planes were isolated within 3DSlicer and exported into ArcGIS as 2D raster images. The extracted rasters were closely associated with the thin sections and so were treated under the same spatial procedures as imagery obtained directly from the thin sections, which are described later in the thesis (see Spatial Registration Procedures).

\section{Example 3D Models of Billet Surface and Internal Structure}

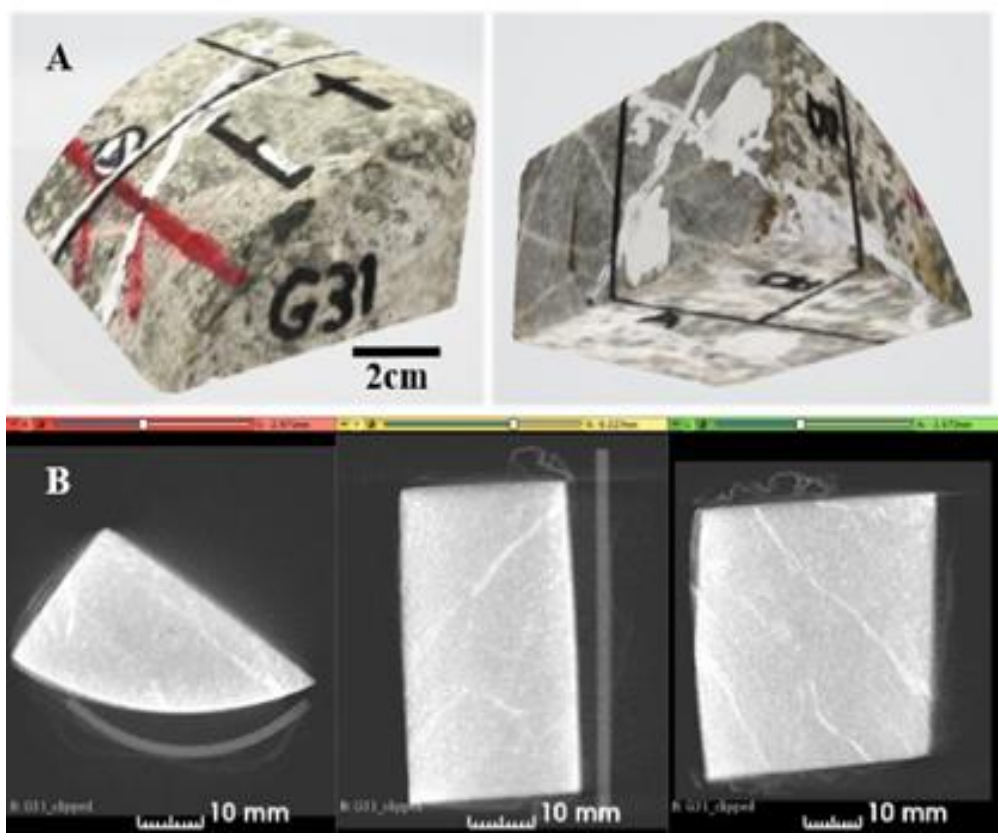

Figure 6. A) Example solid surface model with visible sample number, core-top arrow and orientation line, sectioning lines, and scale bar; and B) Internal structural model, displayed at 3 arbitrary cross-sections from coronal, radial, and sagittal perspective. Both examples represent billet G31. 


\section{X-Ray Diffraction (XRD) Data}

Once the petrographic thin sections were extracted and the fragmented billet

remainders were returned, spectral profiles from XRD analysis were produced for each of the billets. The first step in this process entailed manual powdering of the samples using a mortar and pestle, grinding the material until the powders were as fine and homogeneous as possible. Then, approximately 1 gram of powder from each sample was staged inside the instrument and scanned iteratively for x-ray reflectance counts at incident angles of 10-90 degrees. The tabulated XRD data were exported and plotted as histograms, allowing the characterization of each billet's composition based on peak signatures in the spectral profile which are known to correspond to specific mineral phases.

\section{Data from Petrographic Thin Sections}

Microstructural studies of fault rocks use numerous analytical and imaging techniques to conduct research, many of which produce data that contain spatially dependent information. Utilizing GIS to process these various data is beneficial because it allows them to be integrated with respect to their spatiality 1) within petrographic thin sections, 2) within core billets, and 3) within the arbitrary coordinates of the drill site and borehole. The following section details the collection and spatial integration of optical, SEM, and CL microstructural imagery and numerical data from the SAFOD thin section samples. The optical mosaics of each whole petrographic thin section serve as a base 'map' from which the other data may be appended (Figure 7). 


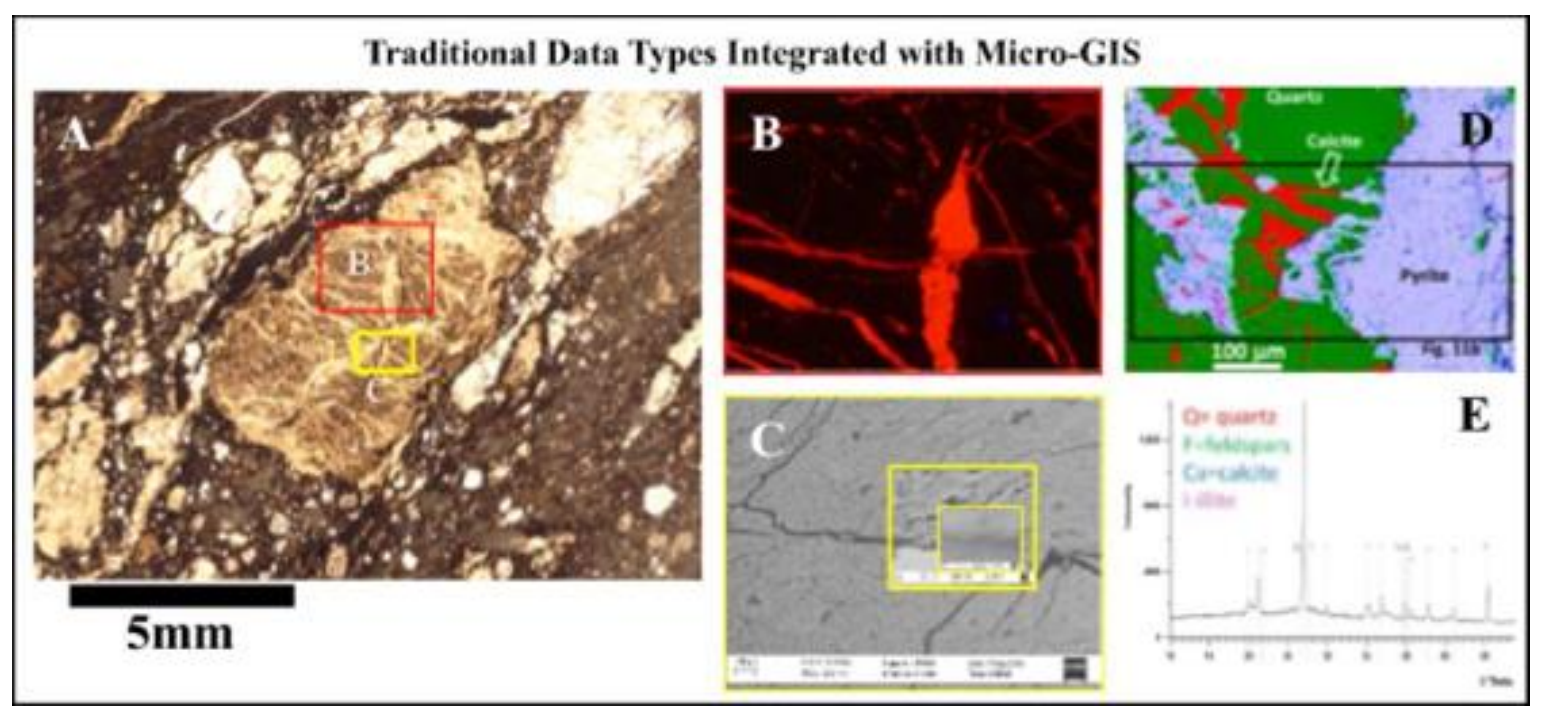

Figure 7. Traditional microstructural data sources including: A) optical thin section mosaic base map; B) CL image from a select region of the thin section; C) SEM images of another region at successively finer magnification; D) EBSD chemical map; and E) XRD spectra indicating mineral content of powdered billet material.

\section{Procedure for Generating Thin Section Base Maps}

Optical mosaics in plain polarized light of each whole thin sections were generated to provide a detailed base map from which other microstructural data are spatially referenced and archived. Once the microscope's focus and lighting were established, each thin section was imaged in a gridded pattern with approximately $30 \%$ vertical and horizontal overlap between images. Overlap was visually determined by using prominent features in the camera's field of view as reference, so overlap deviated slightly throughout imaging. Depending on the aerial extent of the material in the thin sections, 30 - 80 images were required.

Prior to alignment, the images required enhancement to ensure distinct microstructures and seamless boundaries in the mosaic. ImageJ (FIJI 2018) software enabled batch correction of each thin section's whole image set using the 'Normalize Local Contrast' plugin (Saalfeld 2012). This step significantly reduced the number of failed image 
alignments and improved performance during the stitching procedure. Microsoft Image Composite Editor (Microsoft 2015) automated this procedure by identifying common pixels between images and a single mosaic image of each thin section. Adobe Photoshop (Adobe 2015) was used to crop and enhance the contrast of the mosaic images, resulting in the finalized base maps for import into the micro-GIS.

\section{Geodatabase Creation}

ESRI's ArcGIS v10.7.1 software (ESRI 2019) served as the primary environment for integration and visualization of microstructural, compositional, and surface feature data. Its database management architecture and geospatial tools facilitated the creation of twoand three-dimensional representations of digital billet models with respect to their positions in the SAFOD core, and also the position (or superposition) of the various layers of thin section data within the billets. This portion of the thesis covers the steps taken to create the integrated geodatabase, which can be divided into two broad categories: 1) initial establishment of database structure including key administrative settings, import of project data in GIS-supported formats; and 3) defining relationships between the data via spatial referencing.

\section{Establishing Database Structure}

To load and work with the various modes of data in the GIS as effectively as possible, a few considerations needed to be addressed at the outset of database construction. First, a new file geodatabase was created to house the data, relational information, and custom geoprocessing toolkits required for the project. Prior to importing any files, a custom 
arbitrary coordinate system was created and defined as geodatabase's spatial reference grid. This was a crucial step to ensure that data were archived correctly within one shared digital space. Additionally, attribute field domains and topological rules were established to enforce data integrity when importing, displaying, and editing features. Other miscellaneous geodatabase settings were adjusted to suit more specific needs of certain data but are not described in extraneous detail due the multitude of approaches that could be utilized in other micro-GIS endeavors.

At this point, the project imagery and other data were compiled into the geodatabase. This process was facilitated by initially creating an empty feature dataset corresponding to each of the data sources described throughout the paper, allowing them to be imported in batch and with respect to the defined workspace settings. The 3D solid surface models were loaded into a single 'multipatch' feature dataset. The ArcGIS-supported multipatch format reads the vertex, edge, face, and color data contained within the input COLLADA files and reconstructs an identical version of the model. 2D imagery from petrographic thin sections and sliced CT data were stored as raster datasets.

Depending on their nature and purpose, tabulated data were either imported into the geodatabase as stand-alone tables that could be graphically displayed or associated with other features via relationship classes, or joined to the attributes of existing map layers if they contained direct spatial information. The XRD mineral composition plots, for example, were uploaded as stand-alone figures because their spatiality is tied to the whole extent of the corresponding billet, while the CL data table discussed later is tied directly to precise $\mathrm{X}, \mathrm{Y}$ image coordinates and was joined to point features at those locations. 


\section{Spatial Registration Procedures}

Using arbitrary local coordinate systems defined within individual samples, the digital billet models and corresponding thin section-based data could be stored and displayed in 3D space. Given that a reliable measured depth within a core section and the core-top direction for each sample billet is known, it was possible to define the spatial relationships of different samples in a core section using both foliation and distance. This procedure entailed assigning the centroids of the solid surface models to the corresponding placement point at the correct measured depth in local coordinates. Proceeding initial placement, the digital models were scaled using the $2 \mathrm{~cm}$ reference marked on the physical billet prior to imaging. The arrow indicating the up-borehole direction then allowed the models to be oriented relative to the long axis of the core. Lastly, core orientation lines and sectioning planes labeled with respect to the plane of foliation were consulted to establish the radial position of the models with respect to the long axis.

Subsequently, the 3D surface models allowed the planar orientation of petrographic thin section to be defined within the local coordinates of each billet through a visual identification procedure. The planes from which the thin sections were extracted are identifiable in the 'intact' surface models by reference lines labeled on the physical billets prior to sectioning. These sectioning lines appear in photo-realistic color in the solid surface models and are made apparent in the internal structure models by placing elastic bands around the physical billets prior to CT-scanning. Because the physical cut line was visible in both models, the location of the thin section base maps and the corresponding slice of CT data could be approximated. 


\section{$\underline{\text { Cathodoluminescence (CL) Image Analysis }}$}

To emphasize the usefulness of the micro-GIS architecture for database management and spatial analyses, the following section presents a demonstration involving CL imagery captured from a region of interest within one of the petrographic thin section. Analysis of the CL image data within the GIS provides a useful application of the geospatial framework due to the importance of their spatial context. As such, the procedures for generating results from CL data encompass many of the common processing and management tasks within a GIS but are also are well-positioned to benefit from geospatial treatment as they often require tedious and time-consuming work. Herein, we utilize a GIS-based workflow to: 1) archive CL imagery and create point features containing spectral data and additional attribute information; 2) extract spatiallyreferenced information layers from raw spectral data via unsupervised classification of calcite vein generations within a thin section from the SAFOD core.

\section{Point Sampling and Spectral Data Acquisition}

The first component of the demonstration involves spatialized color sampling and wavelength determination of RGB pixels from luminescent areas in the CL image. Areas of interest were predetermined by visual inspection and marked on an annotated copy of the raw image. One or more vein generations are present in each area, which were interpreted based on the presence or absence of significant luminescence contrast and cross-cutting shape relationships (Figure 8). 


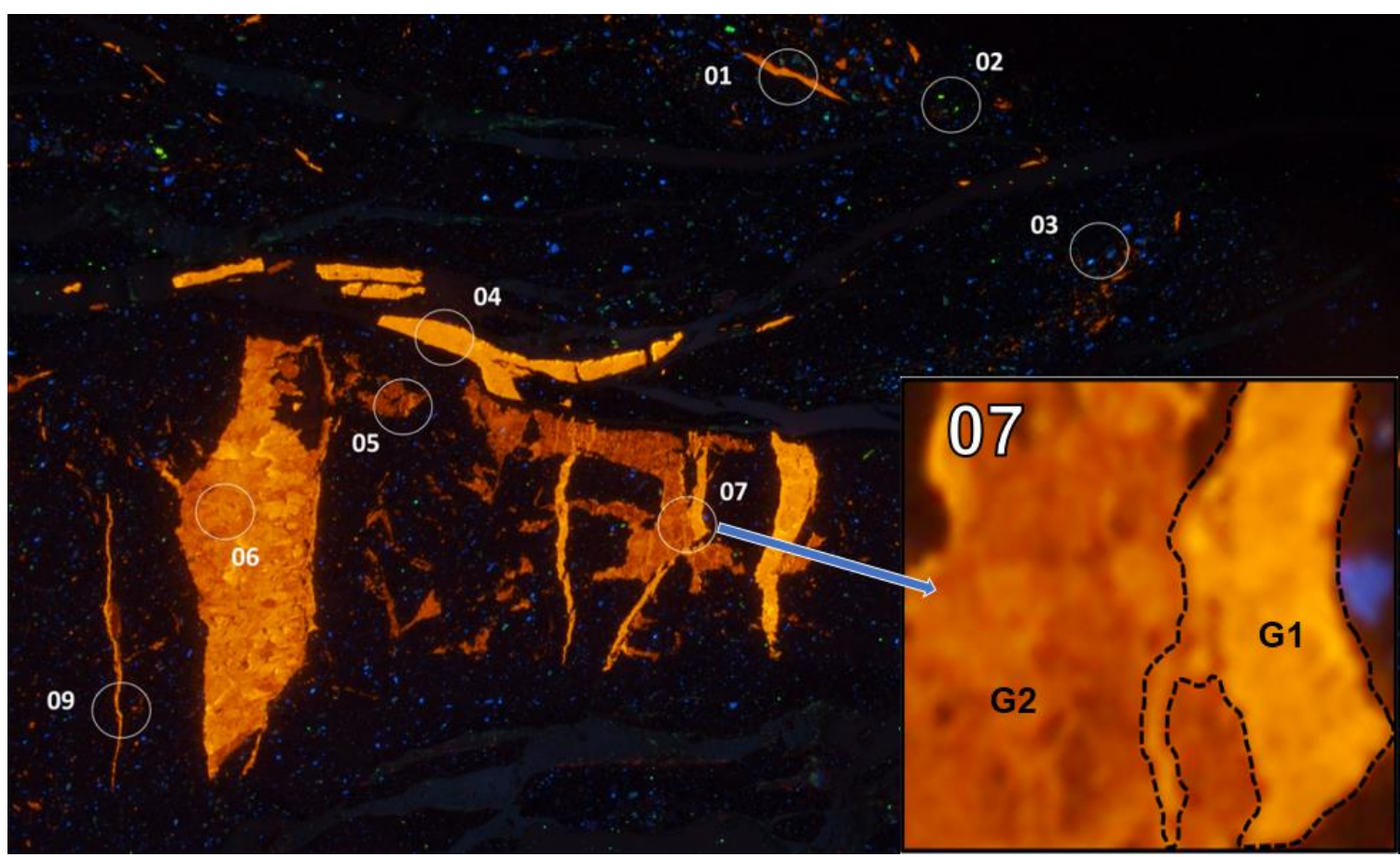

Figure 8. Raw CL image containing two apparent generations of luminescent calcite and pre-determined areas of interest for spectral sampling and data point creation.

The raw, unmarked CL image was then imported into the geodatabase as a raster dataset and any defaults histogram or gamma stretch settings were turned off. Before the precise spatial location of spectral samples could be recorded directly within the local coordinates of the image and assigned attribute information, creation of a feature class to contain the points was required. Following this step, both the CL image and the empty feature class were added to an ArcMap workspace. Navigating through the indicated areas of interest, the lightest and darkest pixel of each apparent vein generation were identified and immediately marked with a corresponding point feature. The vein generation number associated with each pixel sample was also recorded in the points' attributes at this time.

Though CL records light emission from the visible portion of the electromagnetic spectrum $(350-750 \mathrm{~nm})$, it is not possible to quantitatively derive a spectral wavelength from a combination of RGB values. Because 16 million unique hues are possible in the 
study's 8-bit imagery, an extremely high number of RGB combinations exist per each unit wavelength in the $400 \mathrm{~nm}$ spectral range (Smith and Guild 1932; Wyzecki and Styles 1982). Spectral data acquisition from the pixel samples thus required a manual color matching procedure using the CIE 1931 RGB color space standard (CIE 1931) depicted in Figure 9. Using the previously created point locations as a guide, rectangular color swatches were taken from the lightest and darkest pixels of each calcite generation within the areas of interest. Comparing the swatches against the color standard then allowed their corresponding wavelength to be determined. The finalized spectral dataset was then imported to the geodatabase and joined to the attribute table of the mapped point features.

The CIE 1931 sRGB Color Space Standard

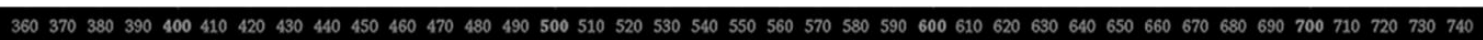

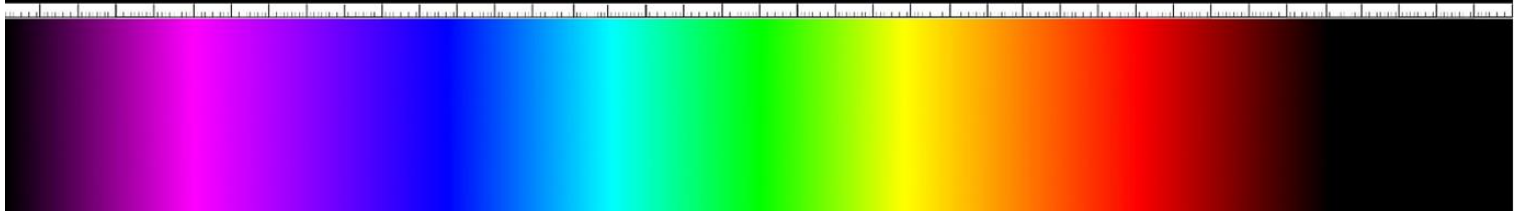

Figure 9. The color standard used for spectral wavelength acquisition from CL image pixels (CIE 1931). CIE - The International Commission on Illumination, or the French Commission International de l'Eclairage, does systematic work in the standardization of human color perception. Their standard consists of a linear stretch of RGB colors with corresponding visible wavelengths given in nanometers.

\section{Unsupervised Classification of Calcite Veins}

The remainder of the micro-GIS demonstration discusses the development of a relatively simple model for CL image classification. As calcite vein generations were the sole target of classification, a fuzzy membership (FM) function was first used to isolate and extract the calcite network and remove all other image pixels from consideration. The FM function calculated the strength of pixel membership based on the mean and standard deviation of the input RGB values (large values were specified as having high 
membership because luminescing calcite contains the brightest pixels in the image), generating a new raster image indicating strength of membership values ranked from 0-1. Permitting fuzzy, or partial, pixel membership is useful for partitioning spectral space where mixed pixels are present, as is the case with the CL image data. The continuous gradient of membership values offers greater flexibility in defining thresholds that determine what pixels are included or excluded in desired information classes (Ahamed, Rao, and Murthy 2000; Foody and Cox 1994; Kent and Mardia 1988).

The membership raster was then used for two distinct purposes: 1) creating a binary dataset indicating if pixels are calcite/not calcite via a simple thresholding procedure, providing a mask for clipping the raw CL image data; and 2) input as an additional image band in the unsupervised classification algorithm (Figure 10).

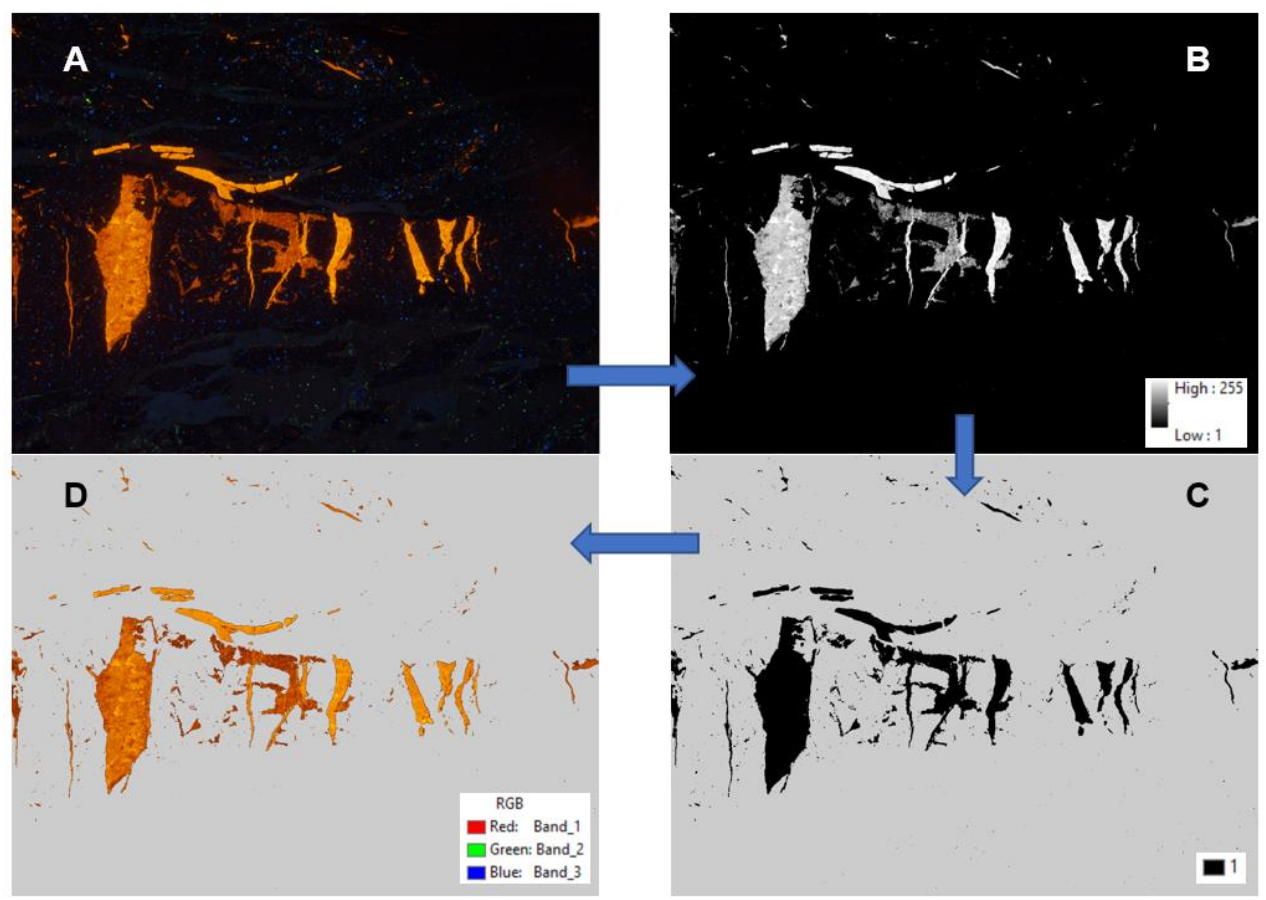

Figure 10. Intermediate data from the classification procedure including: A) the raw CL image; B) the raster band generated via the FM function, with pixel values indication strength of membership; C) the binary mask band produced by thresholding the original FM image; and D) the clipped raster containing RGB pixel values only within the calcite region defined by the mask band. Images B and D serve as the input for the unsupervised classification. 
Calcite vein generations were classified using the ISODATA unsupervised approach, a statistical clustering algorithm that automatically identifies a specified number of spectral classes. Input for the classification consisted of the clipped RGB raster containing only calcite, as well the FM raster (the 0-1 membership values were rescaled to the $0-255$ value range of the 8 -bit RGB pixels), for a total of 4 image bands. The classification was then run with a specified output of 10 spectral classes, which were combined as needed to achieve the final product with 2 apparent calcite vein generations classified.

Accuracy assessment was conducted using 50 random points within each class $(\mathrm{n}=100)$. Because a classified validation image was not available, the points were generated within the clipped raster containing only calcite and then manually assigned to the correct reference class. To reduce the potential for sampling bias, 200 points were initially produced and then reordered using randomly generated numbers. The points were then hand-classified in random until the desired 50 points per class were obtained.

A confusion matrix was then produced to derive quantitative measures of agreement between the classified output and the validation data. Confusion matrices are a widely adopted approach to model validation used not only to quantify classification accuracy, but also to characterize errors resulting from interclass confusion (Foody 2002). Metrics derived from the confusion matrix include: overall accuracy- the number of correctly classified pixels divided by the total number of pixels; producer's accuracy- how often any one class is omitted or misclassified; user's accuracy- how often within a reference class are pixels from other classes misclassified; and the Kappa coefficient- agreement 
between classified and reference samples compensated for chance agreement (Congalton 1991).

The described workflow was implemented using the ArcGIS ModelBuilder visual programming interface (Figure 11). All aspects of the procedure could be performed individually, but ModelBuilder allowed the series of required processing tools to visualized and exported as Python source code. As a result, the classification model can be readily applied to different $C L$ images and with adjusted parameters.

\section{GIS-Based Procedure for CL Image Processing}

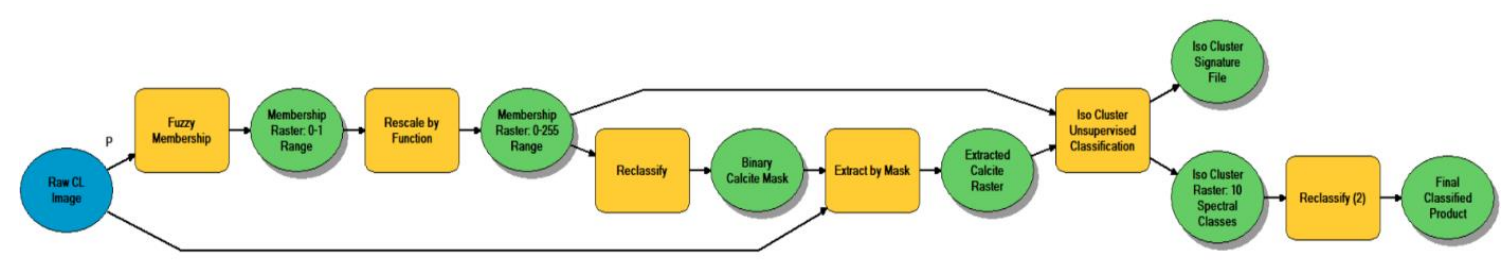

Figure 11. Flow chart of the semi-automated procedure developed in ArcGIS ModelBuilder for detection, extraction, and classification of calcite veins in CL imagery. Blue items correspond to input data, yellow items to processing tools, and green items to derived outputs. 


\section{RESULTS}

The following section details how the proposed micro-GIS method was implemented to integrate, visualize, and examine the data content of the SAFOD sample billets. This study saw the successful development of an ArcGIS database that facilitated efforts to manage and navigate large volumes of microstructural data. The various project data (recounted below) were able to be imported directly into an optimized environment with pre-defined attribute domains, topological constraints, and custom coordinate systems suited for analyses in arbitrary space at centimeter to sub-millimeter scales.

1. 3D solid surface models which provide a geometrically accurate, photorealistic representation of the physical billets;

2. Image slices from 3D internal structure models, which consist of gridded CT data that identify internal characteristics along the sectioning planes of the billets;

3. X-ray diffraction (XRD) histogram plots that characterize the mineralogical composition of the billets;

4. Thin section optical mosaics that serve as a base map layer from which the spatial positions of other thin section-based data can be registered; and

5. SEM-CL image data which contain high-resolution spectral information from areas of interest within the thin sections.

Once imported, all data could be navigated via a catalog and examined individually using the available visualization and spatial analytical tools. However, ArcGIS also lent many beneficial tools for establishing relationships within and between each type of data 
and producing visual representations that effectively conveyed meaningful information. In this study, several of such representations were produced not only to display data but also to provide means for interactive navigation throughout the available information content for all billets.

Navigation begins at the top-most spatial level of the database with a SAFOD core overview map. This map represents the core sections as polygon features and identifies each billet sample location with corresponding points, providing a simplified menu from which additional information can be explored and basic spatial inferences can be made. Arbitrary coordinates for these features were established by adopting their known measured depths as the $y$-axis (the $\mathrm{x}$-axis was only used to define the width of the core polygons). When a point feature for a given billet is selected, the user is presented with an HTML pop-up window containing basic information about the sample. The pop-up window also directly displays the mineral composition plots derived through XRD analysis, which can simply be viewed in the window or downloaded if required. Additionally, any data associated with a given billet may be accessed through hyperlinks in the pop-up (Figure 12a-b).

To view or analyze the 3D solid surface models, they may be traversed to via hyperlink or opened from within the broader database catalog. Doing so opens an ArcScene workspace with the pre-loaded billet model, where the model may be viewed, edited, or subjected to various spatial analyses (Figure 12c). Though the whole 3D internal structure models could not be integrated directly into the database management framework, they could be accessed using hyperlinks within the GIS by providing the path to their 3DSlicer program workspace. 
Pop-up windows for the billet models were configured in similar fashion to the overview map, allowing rapid navigation to the $2 \mathrm{D}$ thin section-based data acquired from within each billet (though I follow a top-down path in this review, note that links were established so that users can explore the interactive menu in any order). Organized on a per-sample basis, thethin section maps contain spatially referenced optical base mosaics, raster slices extracted from along sectioning planes in the billets' internal CT data, and CL images from SEM. The base mosaics establish primary local coordinate systems in which the other map layers are spatially registered (Figure 12d). 
$\mathbf{A}$

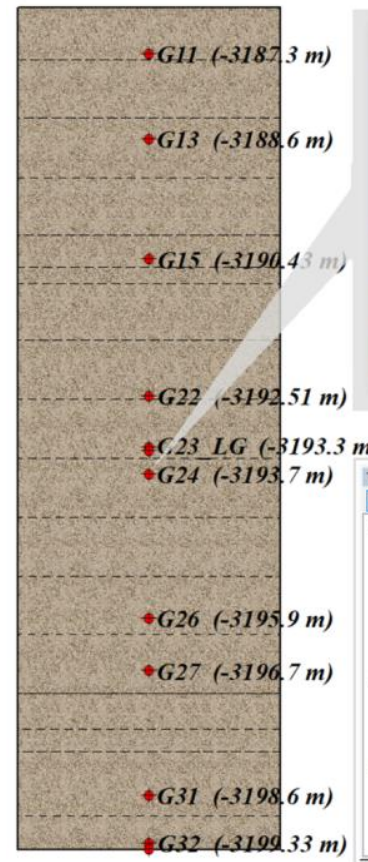

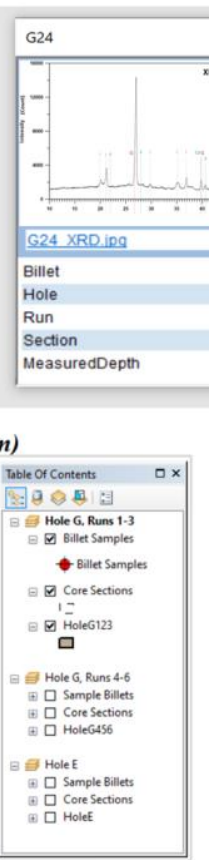

C

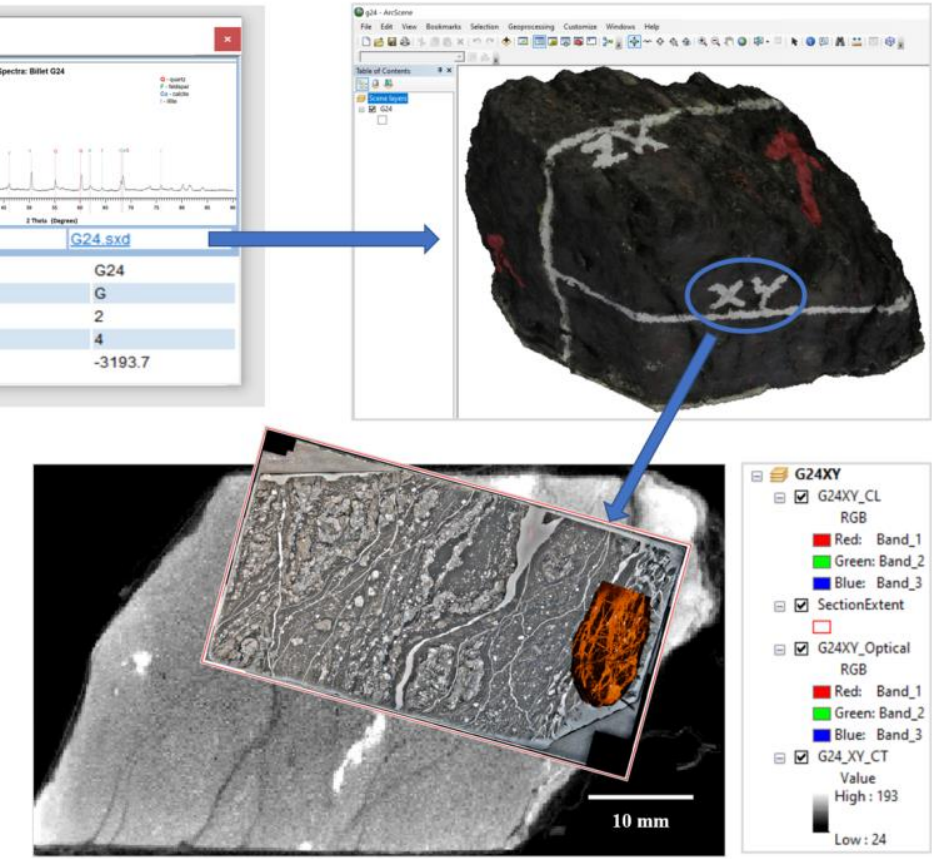

D

Figure 12. Flow diagram illustrating how project microstructural data are structured, visualized and explored interactively within the micro-GIS. The figure depicts A) the SAFOD core overview map showing sample billet locations and attributes; B) An example of the HTML pop-up window containing attribute information, results from XRD analysis, and links to additional data associated with sample billet G24; C) the ArcScene workspace containing billet G24's 3D solid surface model; and D) the spatially referenced 2D image data from a thin section extracted from the XY plane in G24. 


\section{$\underline{\text { CL Image Analysis }}$}

The results of the CL image analysis are discussed in two distinct components: 1) creating and editing of vector point features to facilitate spatialized acquisition of spectral samples; and 2) leveraging geoprocessing tools to develop a streamlined approach for calcite feature extraction, unsupervised classification of vein generations within the extracted calcite, and quantitative accuracy assessment of the classified output.

\section{Spectral Data Points}

Color sampling and wavelength determination using a spatially explicit framework resulted in the creation of tabulated spectral data and their corresponding point locations in the local coordinates of the CL image. The new point features contain XY information, indication of if the sample pertains to calcite or a different luminescent mineral phase, the sample's associated calcite vein generation, and also the wavelength derived by matching pixel color swatches to the CIE 1931 color standard (Figure 13). All listed attributes are of significant interest in various facets of CL-based research but are primarily used in my thesis as a validation dataset for accuracy assessment of the unsupervised classification output obtained in the next portion of the demonstration. However, the procedures outlined for spatial color sampling warranted their own thesis component because they encompassed many important aspects of creating, editing, and displaying vector data in the micro-GIS environment. 


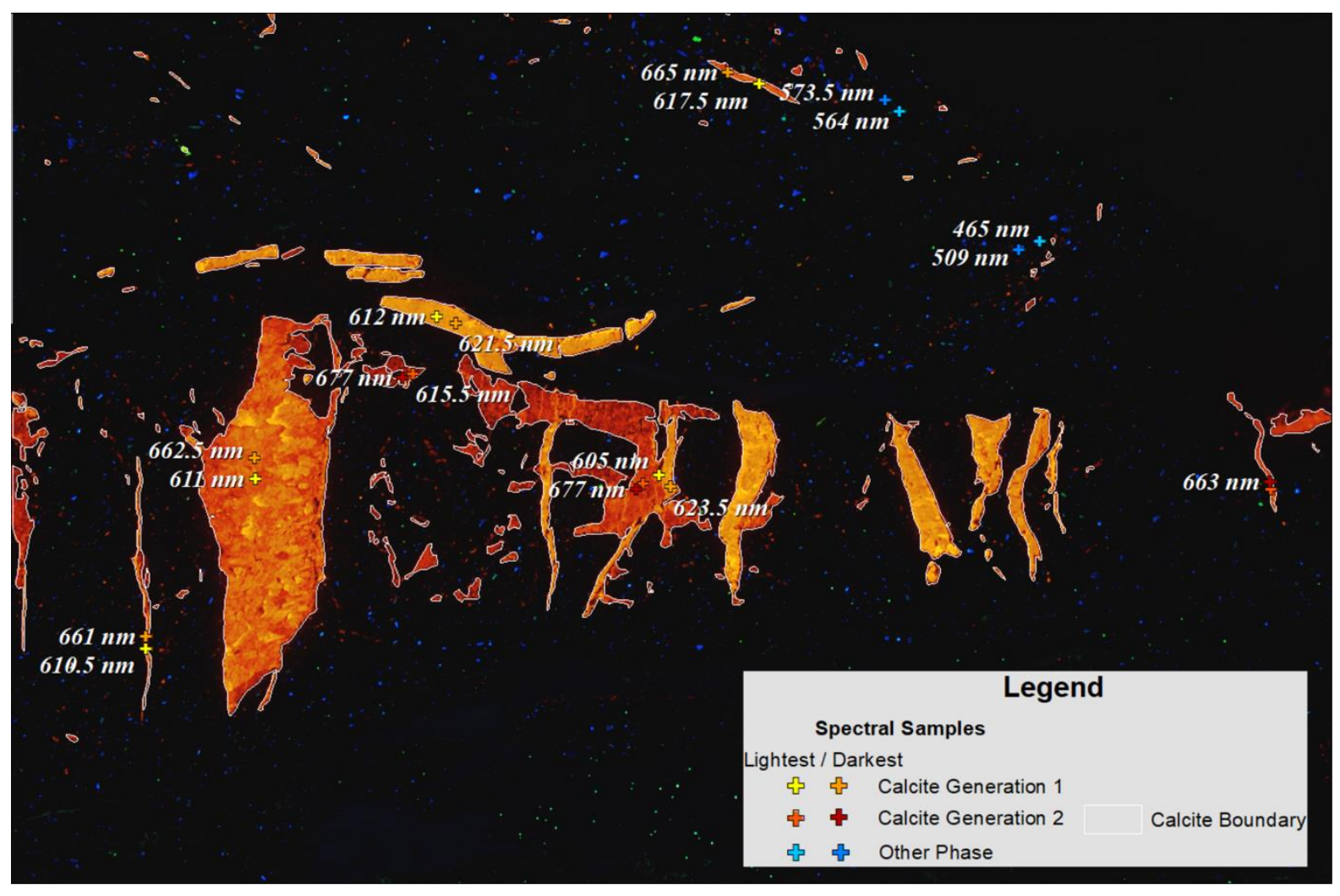

Figure 13. ArcGIS map view of sample points within the local coordinates of the CL image, labeled with custom symbology and relevant attribute information regarding spectral wavelength and calcite vein association.

\section{Classification of Calcite Vein Generations}

The method described for extraction and classification of calcite generations produced two final results: the classified image indicating each pixel's membership in generation 1, 2, or neither; and the transferrable model developed within ArcGIS ModelBuilder to accomplish the procedures. This workflow also generated several intermediate but noteworthy products. These include the additional classification image band derived via a fuzzy membership (FM) function, the binary mask created by thresholding the FM raster, and the image containing only the calcite extracted by applying the mask (see Figure 10).

The FM-derived mask preliminarily classified a total of 318,156 pixels, or approximately $6.5 \%$ of the total image, as calcite. By masking the remainder of the 
image of the image, a significant amount of noise was removed from consideration by the spectral clustering algorithm, resulting in better model performance. Using both the FM raster and the clipped RGB CL image as input bands in the ISODATA classification was also found to produce more desirable spectral classes. The result of this effort is a classified raster image that defines each pixel as either calcite generation 1, calcite generation 2, or background (Figure 14). 


\section{Iso Data Unsupervised Classification of Calcite in RGB Cathodoluminescence (CL) Imagery}
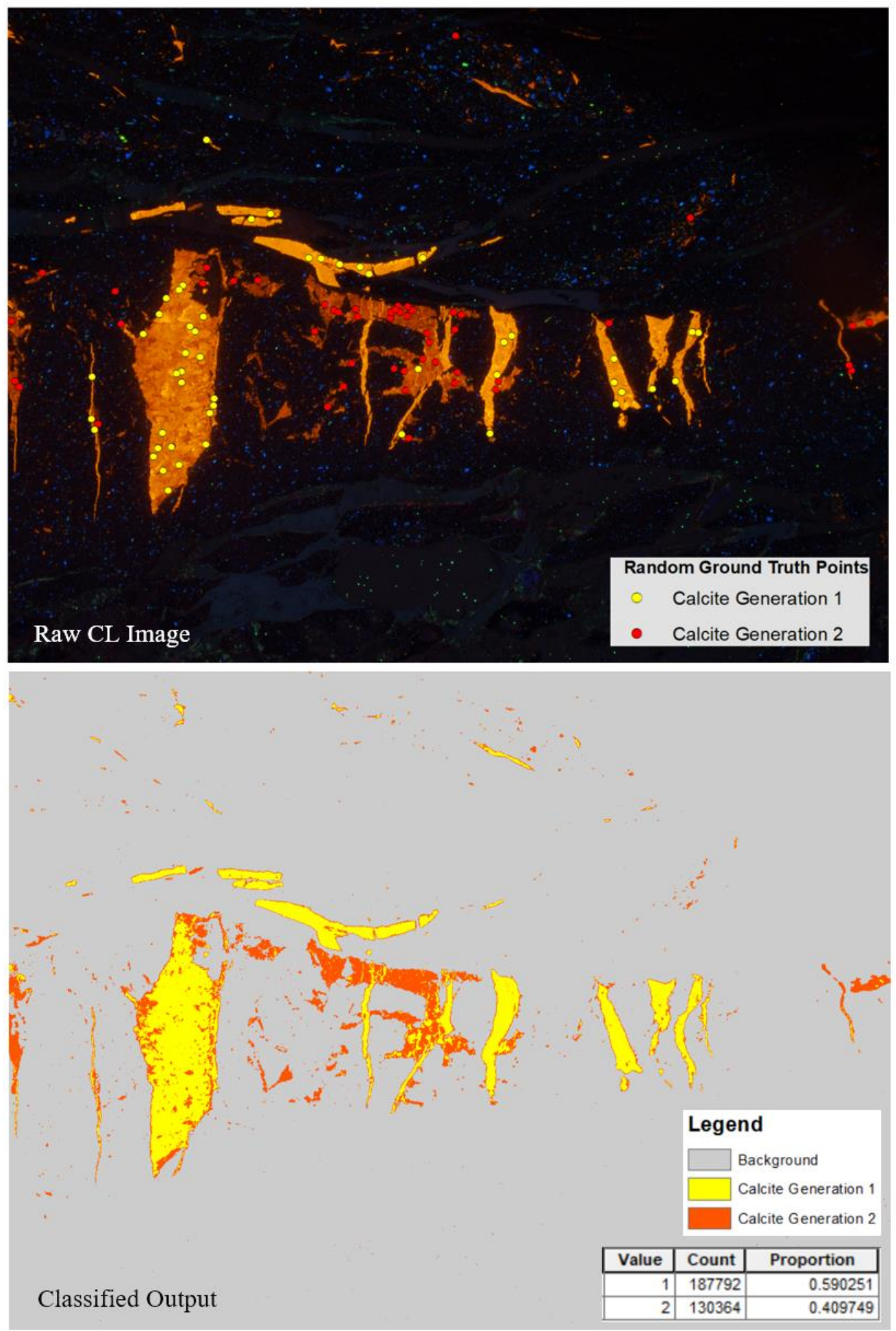

Figure 14. Results of unsupervised classification showing the input CL image, randomly generated accuracy assessment points $(n=100)$, and the classified output with counts of pixels assigned as either calcite generation 1 or 2 . 
The results from accuracy assessment of the classified output are shown in Table 1. These were derived from 100 points (50 points per class) that were randomly generated within the masked calcite and assigned to the correct class. Overall accuracy was reported at $85 \%$ with a Kappa coefficient of $70 \%$. The highest producer's accuracy was observed in the generation 2 class (90\%), while the highest user's accuracy (89\%) was reported in the generation 1 class. These statistics indicate that of the 100 reference points, 85 were classified correctly. Of the 50 points from the generation 1 class, $20 \%$ were mis-classified as generation 2. Likewise, $10 \%$ of generation 2's points were erroneously classified as generation 1 .

\section{Classification Confusion Matrix}

\begin{tabular}{|l|r|r|r|}
\hline Reference & Calcite Generation 1 & Calcite Generation 2 & Total \\
\hline Calcite Generation 1 & 40 & 5 & 45 \\
\hline Calcite Generation 2 & 10 & 45 & 55 \\
\hline Total & 50 & 50 & 100 \\
\hline
\end{tabular}

\begin{tabular}{|l|l|l|}
\hline Producer's Accuracy & 0.80 & 0.90 \\
\hline User's Accuracy & 0.89 & 0.82 \\
\hline
\end{tabular}

\begin{tabular}{|l|r|}
\hline Overall Accuracy & 0.85 \\
\hline Kappa Coefficient & 0.70 \\
\hline
\end{tabular}

Table 1. Results of the confusion matrix analysis providing quantitative accuracy assessment of the unsupervised classification output. 


\section{DISCUSSION}

The procedures described in this thesis were developed to establish a universal framework for spatially explicit integration of 2D and 3D microstructural data obtained from drill core samples. Each of the various stages were ultimately marked with successes, but also identified key challenges that should be addressed in future micro-GIS

efforts. Though SFM reconstruction proved to be a viable path for generating GIS-ready billet models, accurate identification of tie points was strongly dependent upon individual billet characteristics and how the input images were captured. Limitations for storage and 3D rendering of large $\mathrm{CT}$ data sets were also encountered while attempting to incorporate the internal structure from DICOM sections into the geodatabase. The inability to unify both billet models (i.e. the 3D solid surface and CT-scanned volume) in the micro-GIS imposed additional constraints on the level of precision with which thin section-based data could be mapped. Several other facets of the multi-scalar and dimensional spatial referencing also illuminated challenges (not resulting from software limitations) that must be addressed in future studies. The following discussion reviews these difficulties, makes recommendations for future application of micro-GIS to structural geology, and finishes with concluding remarks. 


\section{Digital Modelling to Preserve Physical Records: Successes and Challenges}

\section{Billet Solid Surface Models}

The SFM approach proved very robust for producing high quality 3D models from 2D imagery of the 26 SAFOD sample billets. Despite significant variance in the billets' composition, size, and shape, enough image tie points could ultimately be identified for point cloud densification and subsequent model construction in all samples (Figure 15). The interpolated billet meshes were geometrically adequate for reliable volumetric and surface area estimates. In addition, the image textures were mapped to the faces of the billet model so that visual representations of the billets were successfully preserved after the physical ones had been sectioned and powdered for additional analyses. Lastly, the models met the objective of retaining the necessary reference markings for spatial registration of billets to the drill core and thin section-based data to the billets.
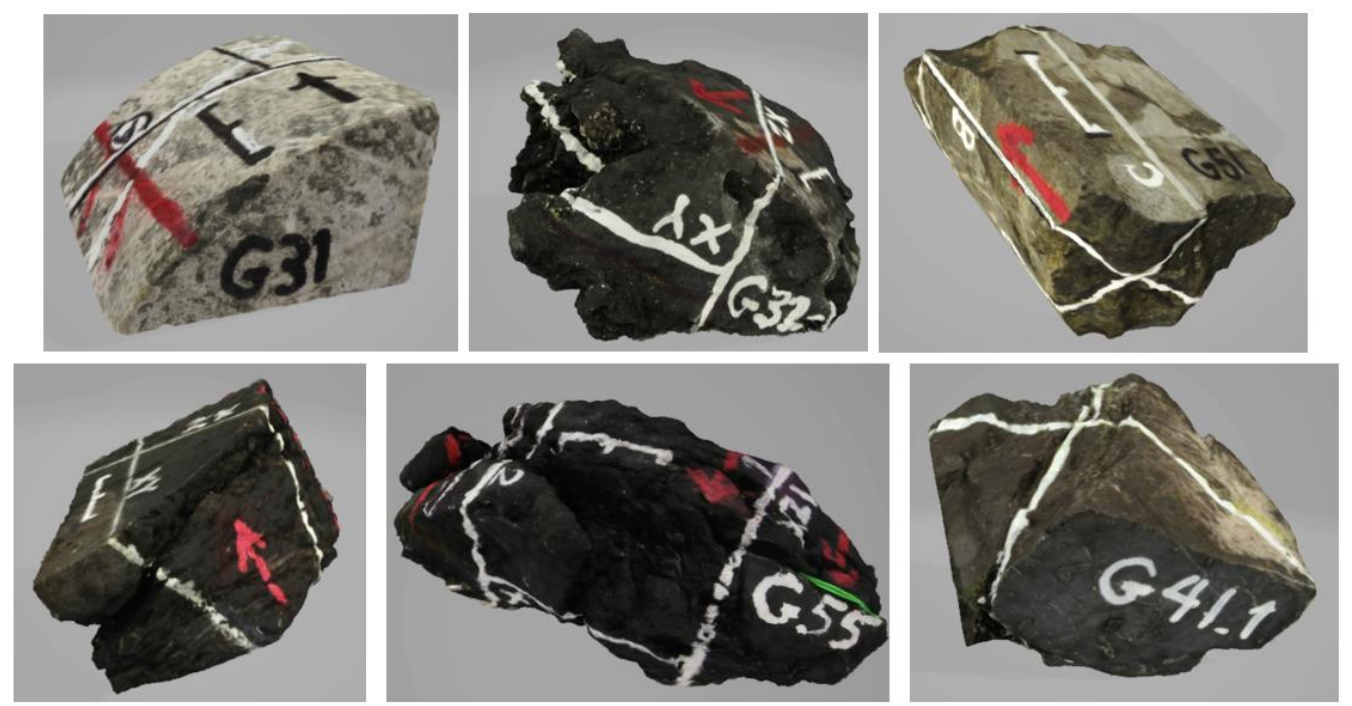

Figure 15. Illustration containing 6 finalized solid surface models, indicating various combinations of the discussed billet reference markings and SFM's flexibility given a wide range of billet composition and geometries.

The modelling process did, however, reveal that the SFM approach is highly sensitive to billet surface texture, camera parameters, and the lighting environment in which 
images were captured. The textures of the SAFOD billets varied widely; some were composed of minerals with a matte color and heterogeneity that provided many potential tie points in each image, while others were primarily black and moderately reflective. Billets with a highly reflective or glossy color, particularly samples impregnated with resin to maintain structural integrity, required extra attention to avoid anomalous light effects that contribute to failed image alignment and inaccurate construction of tie points. If the digital camera was not placed on a low ISO setting, images of those billets were additionally prone to noise from reflective materials.

Although placing the sample in a light diffusion box during imaging was essential, the positioning of the 4 LED lights was found to be equally important. The light sources must be evenly distributed around the diffusion tent to avoid shadows, close enough to illuminate the entire billet but not so close as to create uneven lighting across its surface. Once the ideal placement was determined, fixing the lights in place was beneficial. Additionally, any light emitted from behind the camera's position contributed to glare and reflections, so overhead room lights were turned off and ambient light from windows was minimized.

Despite efforts to carefully control the billet photography environment, some erroneous points were expected in the dense point clouds; these were typically remnants of the sample mount used during imaging, but also occurred along the edges and corners of the billets. However, any undesired points could be manually removed until 'clean' dense point clouds were obtained. In summary, SFM photogrammetry provides a flexible and cost-effective way to obtain accurate 3D solid surface models of drill core billets 
using 2D digital camera imagery if the images were systematically captured and meet the discussed quality standards.

\section{Billet Internal Structure Models}

The CT-scanning procedure also successfully generated 3D datasets containing quantitative structural data from within the 26 billet samples, providing valuable insight on their internal topology. The models could then be rendered as stacks of 2D image slices at a consistent interval throughout the billets using 3DSlicer. Considering the structure models as gridded cube of continuous data, the structural characteristics of each billet are measured at roughly 1 billion or more unique locations, while a single CT measurement corresponds to one voxel with an x-ray reflectance value and a spatial resolution of $55 \mu \mathrm{m}^{3}$. As such, the objective of preserving a digital copy of the billets in their still-intact state was satisfied. The faint x-ray signatures of the elastic bands were also detected within the CT data, in effect identifying the physical cut lines from sectioning helping to establish spatial context while navigating the models.

Rendering and navigating the internal structure models within the 3Dslicer software allowed the billets' CT data along the section planes to be isolated and exported into ArcGIS. Though this procedure supplied raster images that could be displayed and fully manipulated with other data layers in the thin sections, it was not possible to store the complete 3D models in the geodatabase without significant data reduction and vectorization. As a result, the internal structure models could not be unified with the solid surface models under a single shared coordinate system. Were this not the case, the $2 \mathrm{D}$ thin section base maps could be registered in their exact position by identifying tie 
points within the spatially referenced CT data. In the current database structure, however, the thin section base maps are only linked to the centroid of the approximated sectioning planes identified from the solid surface models. In short, a direct link to the 3D internal structure models was not achieved in this study but appears to be feasible with appropriate choice of new and innovative algorithmic tools. Possible solutions to this issue include new programmatic interfaces between ArcGIS and the software used for rendering and navigating entire CT data sets, and general enhancements to software functionality in support of greater data interoperability.

\section{Spatial Referencing}

In the micro-GIS database, the 3D billet models are tied by their centroids to a corresponding placement point at the correct measured depth in a 2D SAFOD core overview map. In other words, the models' centroids are the only precise locations that spatially distinguish the models from one another. In this case the exact distance between billet $A$ 's centroid and billet $B$ 's centroid can be measured, but angles or distances between any two vertices in billet $A$ and $B$ cannot. In future core-based GIS mapping, this study recommends a unique spatial position for individual billets be defined within the geographic coordinates of the drill site by making full use of the geophysical logs recorded during drilling. Doing so would enable geometric transformations that account for the compass bearing of the core segment and the clockwise angular relationship between the billet and core orientation line. This operation would be most accurate for billets that include a portion of the outer round surface of the core; otherwise, the 
clockwise angle must be estimated based on the dip of the foliation plane in the billet's respective core section (Figure 16).

Orientation Framework for SAFOD Borehole and Sample Billets

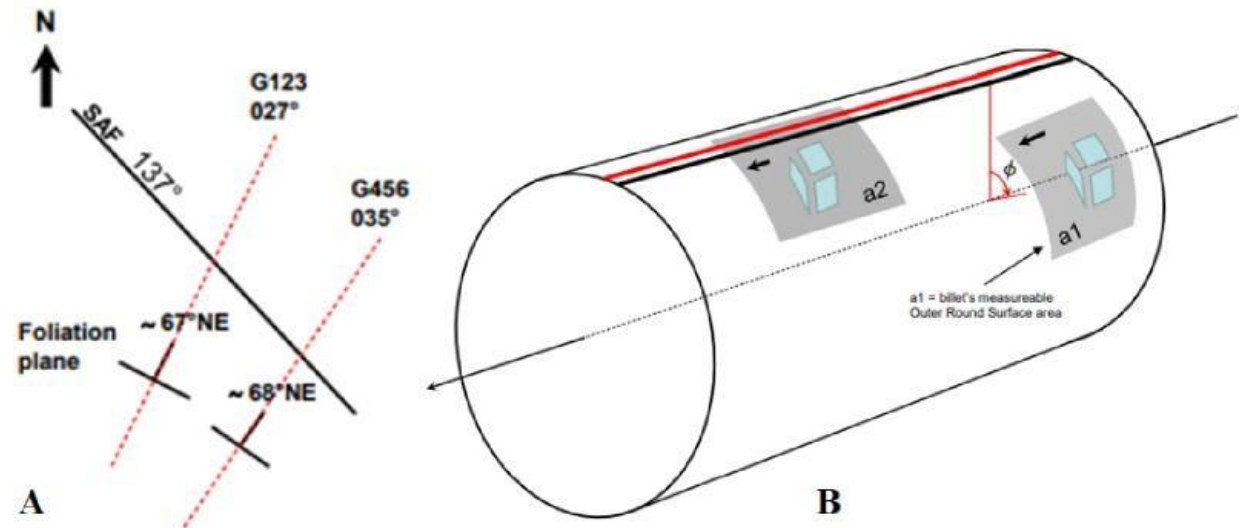

Figure 16. A) Map view of SAF bearing $137^{\circ} \mathrm{SE}$ through California, core sections G123 \& G456 cutting across the SAF with compass bearings of $027^{\circ} \mathrm{NE}$ (plunge of $67^{\circ}$ ) and $035^{\circ} \mathrm{NE}$ (plunge of $68^{\circ}$ ), respectively. B) Schematic depiction of borehole depicting billet clockwise angle with respect to red and black core orientation lines (Hadizadeh 2020 personal communication).

The results of this study indicate that instead of tentative placement of the thin section base maps inside the models, data from thin sections could be mapped within the local 3D coordinate space of the billet model with greater precision. Each pixel in the base maps would then contain a unique XYZ position within both the billet and the borehole at-large. A recent study prescribes a universal system for defining the spatial orientation of petrographic thin sections (Tickoff et al. 2019), which is primarily based on a robust notching procedure that provides all information required for geometric transformation into 3D billet space (Figure 17). Though the authors did not focus on GIS-based implementation of the framework, they have suggested procedures that would complement spatially explicit map visualizations of 3D billet models and 2D thin sectionbased data from optical, SEM, and CL image analyses. 


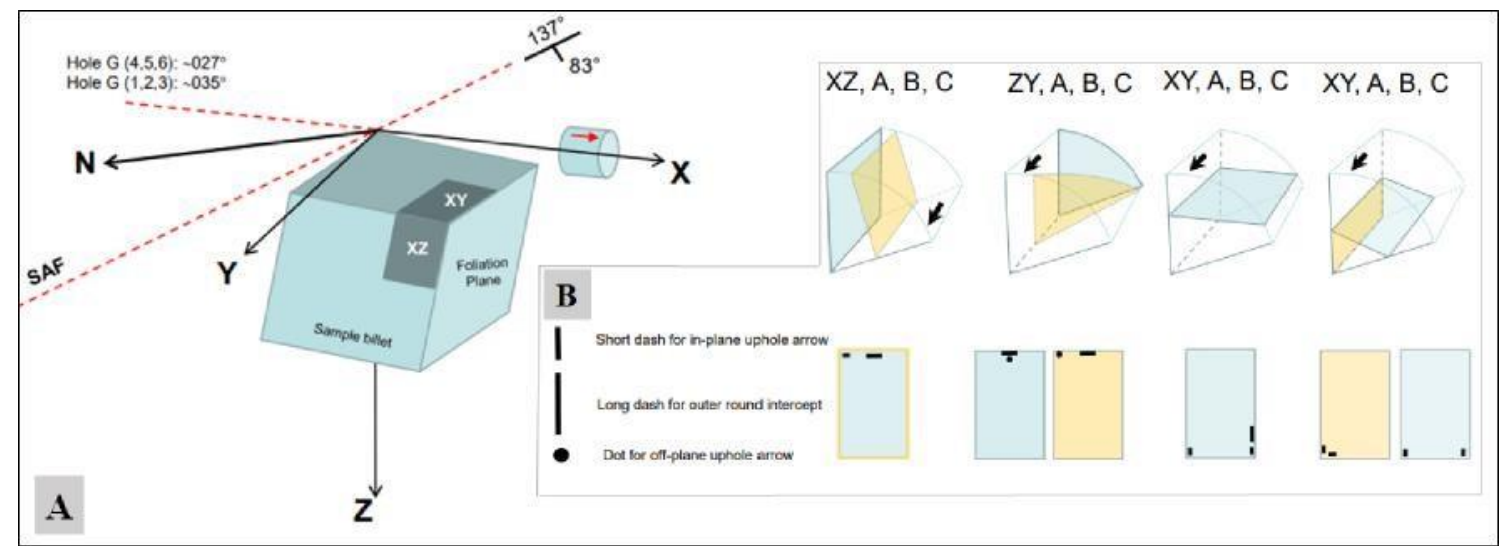

Figure 17. Schematic representation of thin section orientation framework depicting: A) Definition of billet sectioning planes XY, XZ, and YZ with respect to withinbillet foliation plane; and B) Suggested markings to be placed on physical thin sections for spatial referencing within the local coordinates of billet models (adapted after Tickoff et al. 2018).

The potential extensions to the spatial registration framework discussed here could possibly enhance efforts to create geographically translated forms of within-billet and thin section coordinate systems. Though spatial relationships were established to some extent between all data in this study (i.e. the measured depth of the corresponding billet), the use of multiple arbitrary coordinate systems constrained the ability to achieve high spatial precision between billets and also between data products from two or more thin sections within individual billets. Initial efforts were made to establish all billet models within a single local coordinate system representing the dimensions of the SAFOD core, but were hindered by the complex transformations involved in establishing proper billet orientation with respect to the core. Similar complexities were encountered in attempts to transform planar thin section data into the 3D coordinate space of the solid surface models. As such, this study suggests that improved affine transformation matrices should be developed in future studies, with emphasis placed on how they might be more 
seamlessly integrated into the database schema to better facilitate spatial data conversion from local to geographic coordinates.

\section{$\underline{\text { Remote Sensing Techniques Applied to CL Imagery }}$}

This thesis evaluated the applicability of GIS-based remote sensing approaches for classifying calcite in CL imagery. The two-stage classification consisted of first classifying all pixels in the raw image as either calcite or not calcite using a fuzzy membership function, allowing a precise threshold which omitted background pixels, while also retaining the desired calcite pixels, to be determined. The raster containing only calcite was then subjected to the ISODATA unsupervised classification to resolve information classes pertaining to generational growth morphologies within the calcite vein network. Accuracy assessment indicated that the spectral clustering approach identified the correct generation with an $80 \%$ success rate.

The unsupervised model performance served as a preliminary indicator for the viability of common remote sensing techniques and geospatial processing tools for extracting meaningful information from raw spectral data. Furthermore, this suggests that variability and complexity among the raw CL image data can be distilled into discrete categories of greater intuitive value than the heterogeneous pixels that inform them. This is useful in geological analyses because adequate spatial inspection of calcite vein networks often entails significant time investment into tedious procedures. By employing automated or semi-automated remote sensing approaches to identify and segment the veins, relevant information such as pressure and temperature conditions of formation can be attributed to calcite generations as cohesive entities rather than to image 
pixels that are only partial representation of the entities. In addition, classified CL images create new opportunities to visually examine and quantitatively evaluate the spatial characteristics of micro-scale mineralized systems.

Future studies, however, should continue to test the efficacy of other image classification approaches for addressing questions related to $\mathrm{CL}$ and other microstructural image data. A key consideration when determining appropriate approaches is shape as a strong salient characteristic in most calcite vein networks. In other words, there is often strong autocorrelation among near pixels in the images, which is ignored in pixel-wise statistical clustering algorithms such as ISODATA. More advanced, supervised approaches such as random forest classifiers, support vector machines, neural networks, or deep learning (Chaib et al. 2017; Cheng, Han, and Lu 2017; Kussul et al. 2017) could potentially prove more robust ways to approach the salient aspects of calcite veins and achieve classification accuracies greater than those of this study. 


\section{CONCLUSIONS}

Geographic Information Systems (GIS) comprise an established scientific discipline in and of themselves, but are perhaps equally useful when considered as an integrative toolkit that can facilitate spatial data management in all disciplines. A micro-GIS thus serves as an ideal repository and analytical workspace for drill core-based microstructural data that are traditionally compartmentalized. This thesis sought to probe the potential for treatment of those data with the geospatial framework in a study involving 26 sample billets from the San Andreas Fault Observatory at Depth (SAFOD). Multiple forms of 3D and 2D data were integrated in a geodatabase that archived not only the input data, but also their later-defined spatial relationships and outputs derived from spatial analyses. By-products of the method included interactive map visualizations, a hierarchical data catalog based on spatial relationships, and ModelBuilder workflows for accomplishing the various database management and analysis tasks.

Though the research effort was marked with numerous successes, the challenges that persist indicate an agenda for ongoing interdisciplinary research using micro-GIS as the glue. 'Glue' is perhaps the simplest, but nonetheless appropriate, description of the role that geospatial technologies play in science - GIS isn't an outcome, but rather an adhesive tool for creating a whole that is greater than the sum of its parts. As with any glue, however, geospatial tools are not always a one-size-fits-all solution. The spatial and spectral characteristics of microstructural data require different ingredients than those in traditional GIS applications. 
To this end, future structural geology studies should continue prioritizing the spatial relationships within and between the different sources of microstructural data, but also work toward a more standardized vernacular around spatially explicit handling of those data in a GIS framework. For example, civil engineers benefit from tailored analytical toolkits such as 'CityEngine' for 3D modelling and 'Network Analyst' for studies involving infrastructure and transportation data (ESRI 2020). Another case can be observed with hydrology-specific tools for identifying watersheds, estimating the flow and accumulation of surface water, and modelling the path of groundwater contaminants. In similar fashion, custom geoprocessing tools and workspace templates should also be developed to better facilitate structural geologists working at the micro-scale.

This thesis confronted the procedural and conceptual challenges associated with spatial integration of core-based microstructural data, built on recent advances to develop universal micro-GIS procedures, and demonstrated the usefulness of GIS within the broader context of structural geology as a whole. With continued advances on both disciplinary fronts, the novel approaches discussed in this study are well-positioned to inform, and simultaneously be informed by, innovations in the future. 


\section{REFERENCES}

Adobe Photoshop CS. San Jose, CA: Adobe Inc.

Agisoft Metashape Professional Edition, Version 1.5. St. Petersburg, Russia: Agisoft LLC.

Ahamed, T. N., K. G. Rao, and J. S. R. Murthy. 2000. GIS-based fuzzy membership model for crop-land suitability analysis. Agricultural systems 63 (2): 75-95.

ArcGIS, Version 10.7.1. Redlands, CA: ESRI, Inc.

Balaguer-Puig, M., Á. Marqués-Mateu, J. L. Lerma, and S. Ibáñez-Asensio. 2017. Estimation of small-scale soil erosion in laboratory experiments with Structure from Motion photogrammetry. Geomorphology 295: 285-296.

Ball, G. H. and D.J. Hall. 1965. ISODATA, a novel method of data analysis and pattern classification. Menlo Park, CA. Stanford Research Institute.

Barnaby, R. J. and J. D. Rimstidt. 1989. Redox conditions of calcite cementation interpreted from $\mathrm{Mn}$ and Fe contents of authigenic calcites. Geological Society of America Bulletin 101 (6): 795-804.

Barraud, J. 2006. The use of watershed segmentation and GIS software for textural analysis of thin sections. Journal of Volcanology and Geothermal Research 154 (12): 17-33.

Berrezueta, E., M. J. Domínguez-Cuesta, B. Ordóñez-Casado, C. Medina, and R. Molinero. 2017. Pore space quantification of sedimentary rocks before-after supercritical CO2 interaction by optical image analysis. Energy Procedia 114: 43824393.

Bradbury, K. K., J. P. Evans, J. S. Chester, F. M. Chester, and D. L. Kirschner. 2011. Lithology and internal structure of the San Andreas fault at depth based on characterization of Phase 3 whole-rock core in the San Andreas Fault Observatory at Depth (SAFOD) borehole. Earth and Planetary Science Letters 310 (2): 131-144. 
Budd, D. A., U. Hammes, and W. B. Ward. 2000. Cathodoluminescence in calcite cements: New insights on $\mathrm{Pb}$ and $\mathrm{Zn}$ sensitizing, Mn activation, and quenching at low trace-element concentrations. Journal of Sedimentary Research 70 (1): 217-226.

Cammack, J. N., M. J. Spicuzza, A. J. Cavosie, M. J. Van Kranendonk, A. H. Hickman, R. Kozdon, I. J. Orland, K. Kitajima, and J. W. Valley. 2018. SIMS microanalysis of the Strelley Pool Formation cherts and the implications for the secular-temporal oxygen-isotope trend of cherts. Precambrian Research 304: 125-139.

Cazenave S., R. Chapoulie, and G. Villeneuve. 2003. Cathodoluminescence of synthetic and natural calcite: the effects of manganese and iron on orange emission. Mineralogy and Petrology 78, 243-253.

Chaib, S., H. Yao, Y. Gu, and M. Amrani. 2017. Deep feature extraction and combination for remote sensing image classification based on pre-trained CNN models. In Ninth International Conference on Digital Image Processing 104203D. International Society for Optics and Photonics.

Chan, M. A., S. E. Peters, and B. Tikoff. 2016. The future of field geology, open data sharing and cybertechnology in Earth science. Sediment Record 14: 4-10.

Cheng, G., J. Han, and X. Lu. 2017. Remote sensing image scene classification: Benchmark and state of the art. Proceedings of the IEEE 105 (10): 1865-1883.

Coenen, J., E. Tchouparova, and X. Jing. 2004. Measurement parameters and resolution aspects of micro X-ray tomography for advanced core analysis. International Symposium of the Society of Core Analysts: 256-261.

Congalton, R. G. 1991. A review of assessing the accuracy of classifications of remotely sensed data. Remote Sensing of Environment 37 (1): 35-46.

Cullity, B. D. 1956. Elements of X-ray Diffraction. Reading, MA. Addison-Wesley Publishing.

Davidson, M. W. and G. E. Lofgren. 1991. Photomicrography in the geological sciences. Journal of Geological Education 39 (5): 403-418.

Edward, J. and D.J. Biddle. 2017. Using geographic information systems (GIS) to examine barriers to healthcare access for Hispanic and Latino immigrants in the US south. Journal of racial and ethnic health disparities 4 (2): 297-307.

Fairchild, I. J. 1983. Chemical controls of Cathodoluminescence of natural dolomites and calcite: new data and review. Sedimentology 30: 579-583. 
Fedorov A., R. Beichel, J. Kalpathy-Cramer, J. Finet, J. C. Fillion-Robin, S. Pujol, C. Bauer, D. Jennings, F. M. Fennessy, M. Sonka, J. Buatti, S. R. Aylward, J. V. Miller, S. Pieper, and R. Kikinis. 2012. 3D Slicer as an Image Computing Platform for the Quantitative Imaging Network. Magnetic Resonance Imaging 30 (9): 1323-1341.

Foody, G. M. 2002. Status of land cover classification accuracy assessment. Remote sensing of environment 80 (1): 185-201.

Foody, G. M. and D. P. Cox. 1994. Sub-pixel land cover composition estimation using a linear mixture model and fuzzy membership functions. Remote sensing 15 (3): 619631.

Gaughan, A .E., F. R. Stevens, C. Linard, P. Jia, and A. J. Tatem. 2013. High resolution population distribution maps for Southeast Asia in 2010 and 2015. PloS one 8 (2): e55882.

Götze, J. 2002. Potential of cathodoluminescence (CL) microscopy and spectroscopy for the analysis of minerals and materials. Analytical and bioanalytical chemistry 374 (4): 703-708.

Haaland, M. M., D. E. Friesem, C. E. Miller, and C. S. Henshilwood. 2017. Heat-induced alteration of glauconitic minerals in the Middle Stone Age levels of Blombos Cave, South Africa: Implications for evaluating site structure and burning events. Journal of Archaeological Science 86: 81-100.

Habermann D. 2002. Quantitative Cathodoluminescence (CL) spectroscopy of minerals: possibilities and limitations. Mineralogy and Petrology 76: 247-259.

Hadizadeh, J., S. Mittempergher, J. P. Gratier, F. Renard, G. Di Toro, J. Richard, and H.A. Babaief. 2012. A microstructural study of fault rocks from the SAFOD: Implications for the deformation mechanisms and strength of the creeping segment of the San Andreas Fault. Journal of Structural Geology 42: 246-260.

Hadizadeh, J. and A. P. Boyle. 2018. A study of secondary pyrite deformation and calcite veins in SAFOD damage zone with implications for aseismic creep deformation mechanism at depths $>3$ km. Journal of Structural Geology 117: 14-26.

Richard Hartley, R. and A. Zisserman. 2004. Multiple View Geometry in Computer Vision, Second Edition, Cambridge, UK. Cambridge University Press.

Hassanpour, R. 2012. The use of ArcGIS for determination of quartz optical axis orientation in thin section images. Journal of Microscopy 245 (3): 276-287. 
Hofmann, H., G. Zimmermann, M. Farkas, E. Huenges, A. Zang, M. Leonhardt, G. Kwiatek, P. Martinez-Garzon, M. Bohnhoff, K. Min, P. Fokker, R. Westaway, F. Bethmann, P. Meier, K.S.Yoon, J.W.Choi, T.J. Lee, K.Y. Kim. 2019. First field application of cyclic soft stimulation at the Pohang Enhanced Geothermal System site in Korea. Geophysical Journal International 217 (2): 926-949.

Holdsworth, R. E., E. W. E. Van Diggelen, C. J. Spiers, J. H. P. De Bresser, R. J. Walker, and L. Bowen. 2011. Fault rocks from the SAFOD core samples: implications for weakening at shallow depths along the San Andreas Fault, California. Journal of Structural Geology 33 (2): 132-144.

Hupp, B. N. and J. J. Donovan. 2018. Quantitative mineralogy for facies definition in the Marcellus Shale (Appalachian Basin, USA) using XRD-XRF integration. Sedimentary Geology 371: 16-31.

Image Composite Editor Version 2.0.3. 2015. Redmond, WA. Microsoft Corporation.

ImageJ (FIJI) 1.52P. 2018. Bethesda, MD, USA. Rasband, W. and US National Institutes of Health.

International Continental Scientific Drilling Program. 2020. Drilling Projects. Available at https://www.icdp-online.org/projects/ (last accessed 16 May 2020).

Janssen, C., R. Wirth, A. Reinicke, E. Rybacki, R. Naumann, H. R. Wenk, and G. Dresen. 2011. Nanoscale porosity in SAFOD core samples (San Andreas Fault). Earth and Planetary Science Letters 301 (1-2): 179-189.

Jensen, J. R. 2015. Introductory Digital Image Processing: A Remote Sensing Perspective. New Jersey, USA. Prentice-Hall Inc.

Kent, J. T. and K. V. Mardia. 1988. Spatial classification using fuzzy membership models. IEEE Transactions on Pattern Analysis and Machine Intelligence 10 (5): 659-671.

Kussul, N., M. Lavreniuk, S. Skakun, and A. Shelestov. 2017. Deep learning classification of land cover and crop types using remote sensing data. IEEE Geoscience and Remote Sensing Letters 14 (5): 778-782.

Lee, S. and H. Xu. 2017. Powder XRD and TEM study on crystal structure and interstratification of Zn-chlorite (baileychlore). Powder Diffraction 32 (2): 118-123. 
Lin, B. and A.B. Cerato. 2014. Applications of SEM and ESEM in Microstructural Investigation of Shale-Weathered Expansive Soils along Swelling-Shrinkage Cycles. Engineering Geology 177: 66-74.

Lezzerini, M., F. Antonelli, S. Columbu, R. Gadducci, A. Marradi, D. Miriello, and A. Lazzeri. 2016. Cultural heritage documentation and conservation: Three-dimensional (3D) laser scanning and Geographical Information System (GIS) techniques for thematic mapping of facade stonework of St. Nicholas Church (Pisa, Italy). International Journal of Architectural Heritage 10 (1): 9-19.

Linzmeier, B. J., K. Kitajima, A. C. Denny, and J. N. Cammack. 2018. Making maps on a micrometer scale. Eos 99.

Lucieer, A., S.M.D. Jong, and D. Turner. 2014. Mapping landslide displacements using Structure from Motion (SfM) and image correlation of multi-temporal UAV photography. Progress in Physical Geography 38 (1): 97-116.

Ma, K., H. Tanaka, S. Song, C. Wang, J. Hung, Y. Tsai, J. Mori, Y. Song, E. Yeh, W. Soh, H. Sone, L. Kuo, and H. Wu. 2006. Slip zone and energetics of a large earthquake from the Taiwan Chelungpu-fault Drilling Project. Nature 444: 473-476.

Maggiori, E., Y. Tarabalka, G. Charpiat, and P. Alliez. 2016. Convolutional neural networks for large-scale remote-sensing image classification. IEEE Transactions on Geoscience and Remote Sensing 55 (2): 645-657.

Malczewski, J. 2004. GIS-based land-use suitability analysis: a critical overview. Progress in planning 62 (1): 3-65.

Mather, P. M. and M. Koch. 2011. Computer processing of remotely-sensed images: an introduction. Chichester, West Sussex, UK. John Wiley \& Sons.

Maxwell, A. E., T.A. Warner, and F. Fang. 2018. Implementation of machine-learning classification in remote sensing: An applied review. International Journal of Remote Sensing 39 (9): 2784-2817.

Mees, F., R. Swennen, M. Van Geet, and P. Jacobs. 2003. Applications of X-ray computed tomography in the geosciences. Geological Society, Special Publications 215 (1): 1-6.

Memarsadeghi, N., D. M. Mount, N. S. Netanyahu, and J. LeMoigne. 2007. A fast implementation of the ISODATA clustering algorithm. International Journal of Computational Geometry \& Applications 17 (01): 71-103. 
Murphy, D.B. 2006. Fundamentals of light microscopy. In: Fundamentals of light microscopy and electronic imaging. New York, NY. John Wiley and Sons, Inc.

Ortolano, G., R. Visalli, G. Godard, and R. Cirrincione. 2018. Quantitative X-ray Map Analyser (Q-XRMA): A new GIS-based statistical approach to Mineral Image Analysis. Computers and Geosciences 115: 56-65.

Reches, Z. and H. Ito. 2007. Scientific Drilling of Active Faults: Past and Future. In: Harms, U., C. Koeberl, M.D. Zoback (eds.) Continental Scientific Drilling. Berlin, Heidelberg. Springer.

Reed, S.J. 2005. Electron Microprobe Analysis and Scanning Electron Microscopy in Geology. Cambridge University press.

Renter, J. A. 1989. Applications of computerized tomography in sedimentology. Marine Georesources \& Geotechnology 8 (3): 201-211.

Robinson, I. K. and D. J. Tweet. 1992. Surface X-ray diffraction. Reports on Progress in Physics 55 (5): 599-651.

Rose, G. ed. 2012. Visual Methodologies: An Introduction to Researching with Visual Materials. SAGE Publications.

SAFOD Core Photo Atlas, Version 3. National Science Foundation.

Saalfeld, S. 2012. ImageJ: Enhance Local Contrast (CLAHE). Available at https://imagej.net/Enhance_Local_Contrast_(CLAHE) (last accessed 24 July 2020).

Schleicher, A. M., B. A. Van der Pluijm, and L. N. Warren. 2012. Chlorite-smectite clay minerals and fault behavior: New evidence from the San Andreas Fault Observatory at Depth (SAFOD) core. Lithosphere 4 (3): 209-220.

Smith, K. C. A. and C. W. Oatley. 1955. The scanning electron microscope and its fields of application. British Journal of Applied Physics 6 (11): 391-399.

Smith, T. and J. Guild. 1932. The C.I.E. colorimetric standards and their use. Transactions of the Optical Society 33 (3): 73-134.

Solum, J. G., S. H. Hickman, D. A. Lockner, D. E. Moore, B. A. van der Pluijm, A. M. Schleicher, and J. P. Evans, 2006. Mineralogical characterization of protolith and fault rocks from the SAFOD main hole. Geophysical Research Letters 33 (21). 
Tarquini, S. and M. Favalli. 2010. A microscopic information system (MIS) for petrographic analysis. Computers \& Geosciences 36 (5): 665-674.

Tavakoli, D. A. 2020. X-Ray Diffraction (XRD) for the Analysis of Thin Films. Southeastern Nanotechnology Infrastructure Corridor Technical Webinar Series. Georgia Tech Library.

Tickoff, B., V. Chatzaras, J. Newman, and N. M. Roberts. 2019. Big data in microstructure analysis: Building a universal orientation system for thin sections. Journal of Structural Geology 125: 226-234.

Tobin, H., H. Ito, J. Behrmann, S. Hickman, and G. Kimura. 2007. Joint IODP-ICDP Workshop Examines Challenges of Fault Zone Drilling. Scientific Drilling (special issue 1).

Trimby, P. W. and D. J. Prior. 1999. Microstructural imaging techniques: a comparison between light and scanning electron microscopy. Tectonophysics 303 (4): 71-81.

Verhaert, G., P. Muchez, M. Sintubin, D. Similox-Tohon, S. Vandycke, E. Keppens, E. J. Hodge, and D. A. Richards. 2004. Origin of palaeo-fluids in a normal fault setting in the Aegean region. Geofluids 4: 300-314.

Walker, J. D., B. Tikoff, J. Newman, R. Clark, J. Ash, J. Good, E. G. Bunse, A. Möller, M. Kahn, R. T. Williams, Z. Michels, J. E. Andrew, C. Rufledt. 2019. StraboSpot data system for structural geology. Geosphere 15 (2): 533-547.

Wallace, L., A. Lucieer, Z. Malenovský, D. Turner, and P. Vopěnka. 2016. Assessment of forest structure using two UAV techniques: A comparison of airborne laser scanning and structure from motion (SfM) point clouds. Forests 7 (3): 62-78.

Westoby, M. J., J. Brasington, N. F. Glasser, M. J. Hambrey, and J. M. Reynolds. 2012. 'Structure-from-Motion' photogrammetry: A low-cost, effective tool for geoscience applications. Geomorphology 179: 300-314.

Whitmeyer, S., M. Feely, D. D. Paor, R. Hennessy, S. Whitmeyer, J. Nicoletti, B. Santangelo, J. Daniels, and M. Rivera. 2009. Visualization techniques in field geology education: A case study from western Ireland. The Geological Society of America: Special Paper 461.

Whittig, L. D. and W. R. Allardice. 1986. Principles of X-ray diffraction. In A. Klute (ed.) Methods of soil analysis, Part 1, 2nd ed. Madison, WI. Wiley. 
Willard, R. J. and J. R. McWilliams. 1969. Microstructural techniques in the study of physical properties of rock. International Journal of Rock Mechanics and Mining Sciences \& Geomechanics Abstracts 6 (1): 1-12.

Wohlmutter, C. 2017. GIS based 4D Petroleum-Environment modeling and visualization for optimizing the interdisciplinary petroleum exploration. In 16th International Conference on Geoinformatics-Theoretical and Applied Aspects 2017 (1): 1-5.

Wyzecki, G. and W. S. Stiles. 1982. Color Science 8. New York, NY, USA. Wiley.

Yingkui, L., C. M. Onasch, and Y. Guo. 2008. GIS-based detection of grain boundaries. Journal of Structural Geology 30 (4): 431-443.

Yoon, J., H. Kim, S. H. Sim, and S. Pyo. 2020. Characterization of Porous Cementitious Materials Using Microscopic Image Processing and X-ray CT Analysis. Materials 13 (14): 3105-3121.

Zhang, H. and M.P. Peterson. 2007. A spatial analysis of neighborhood crime in Omaha, Nebraska using alternative measures of crime rates. Internet Journal of Criminology 31: $1-31$.

Zhao, C. X. and L. X. Qian. 2004. Comparative Study of Supervised and Unsupervised Classification in Remote Sensing Image. Journal of Henan University, Natural Science 3.

Zhou, X., D. Liu, H. Bu, L. Deng, H. Liu, P. Yuan, and H. Song. 2018. XRD-based quantitative analysis of clay minerals using reference intensity ratios, mineral intensity factors, Rietveld, and full pattern summation methods: A critical review. Solid Earth Sciences 3 (1): 16-29.

Zoback, M., S. Hickman, and W. Ellsworth. 2011. Scientific Drilling Into the San Andreas Fault Zone--An Overview of SAFOD's First Five Years. Scientific Drilling (11): 1-5.

3D Slicer Version 4.10.2. Available at https://www.slicer.org/ (last accessed 24 July 2020). 


\section{APPENDIX A}

Instruments utilized for data collection 

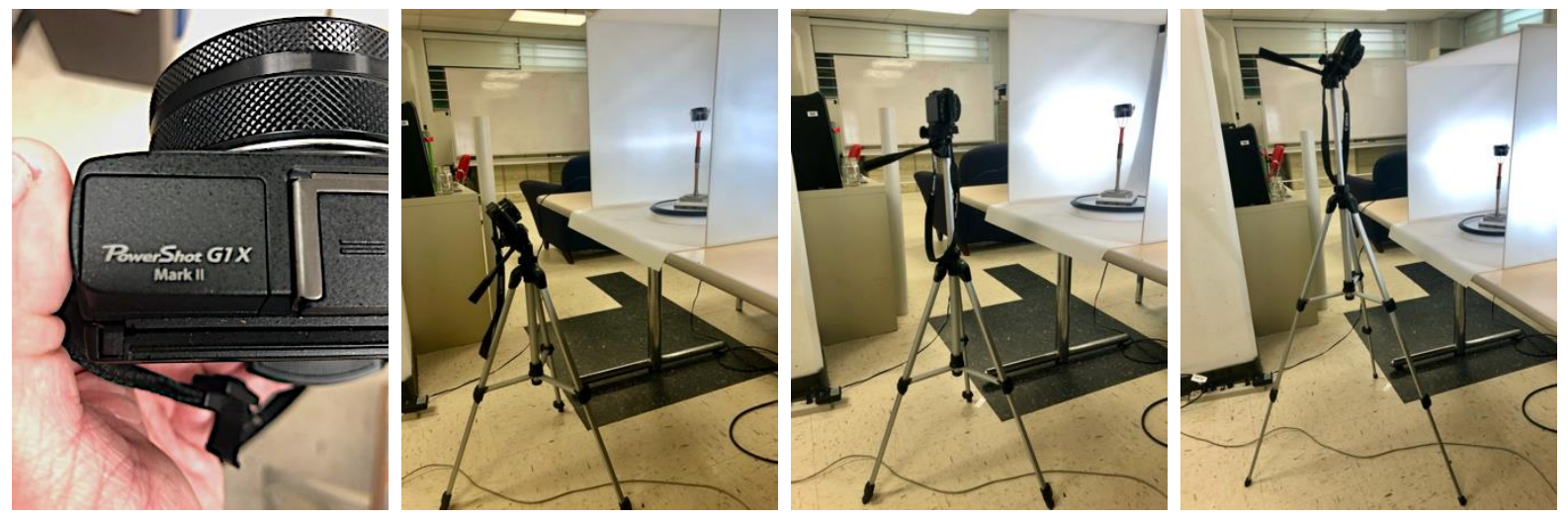

Instrumentation used in billet imaging for SFM reconstruction: Canon Powershot G1 X Mark II digital camera, adjustable camera tripod, desktop light diffusing tent, and custom-made sample mount.

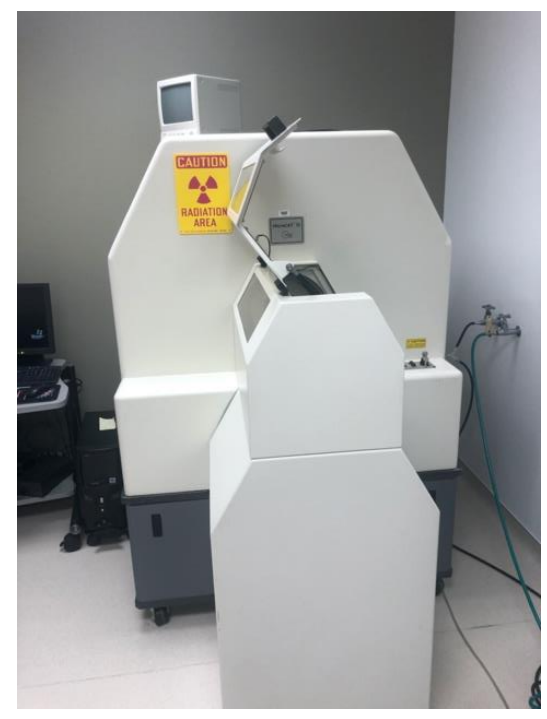

Micro-CT scanner used to obtain billet internal structural data: ImTek MicroCAT II. Scans were performed by Huaiyu Zhang at the Clinical and Translational Research Building at the University of Louisville. 

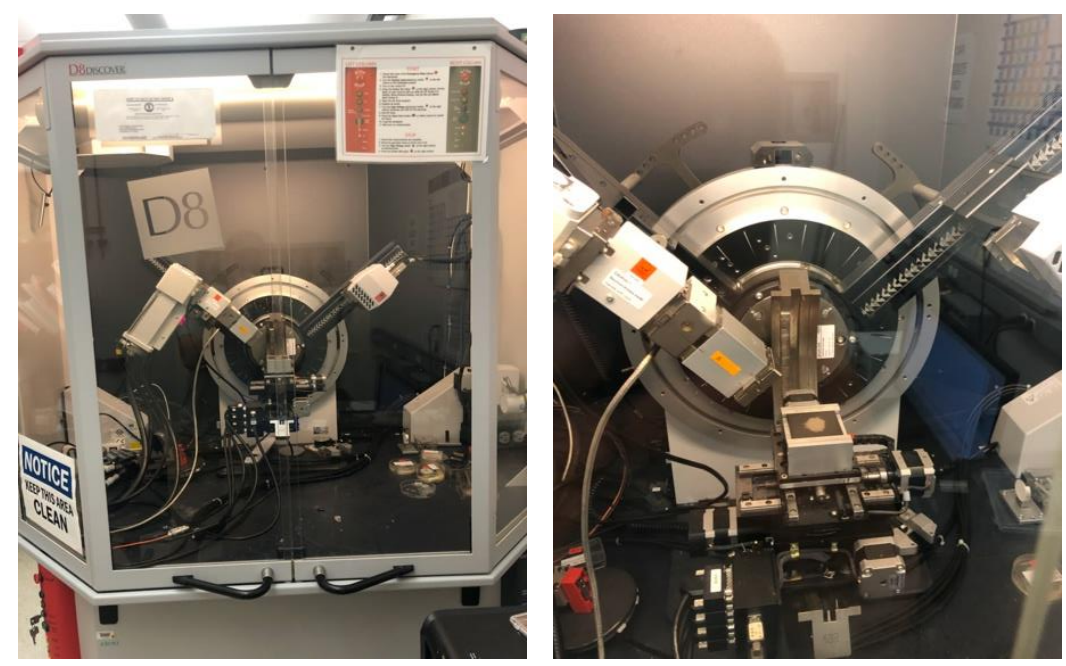

Instrumentation used for XRD data collection: Bruker D8 Discover X-Ray Diffractometer, housed at the Conn Center for Renewable Energy Research at the University of Louisville.
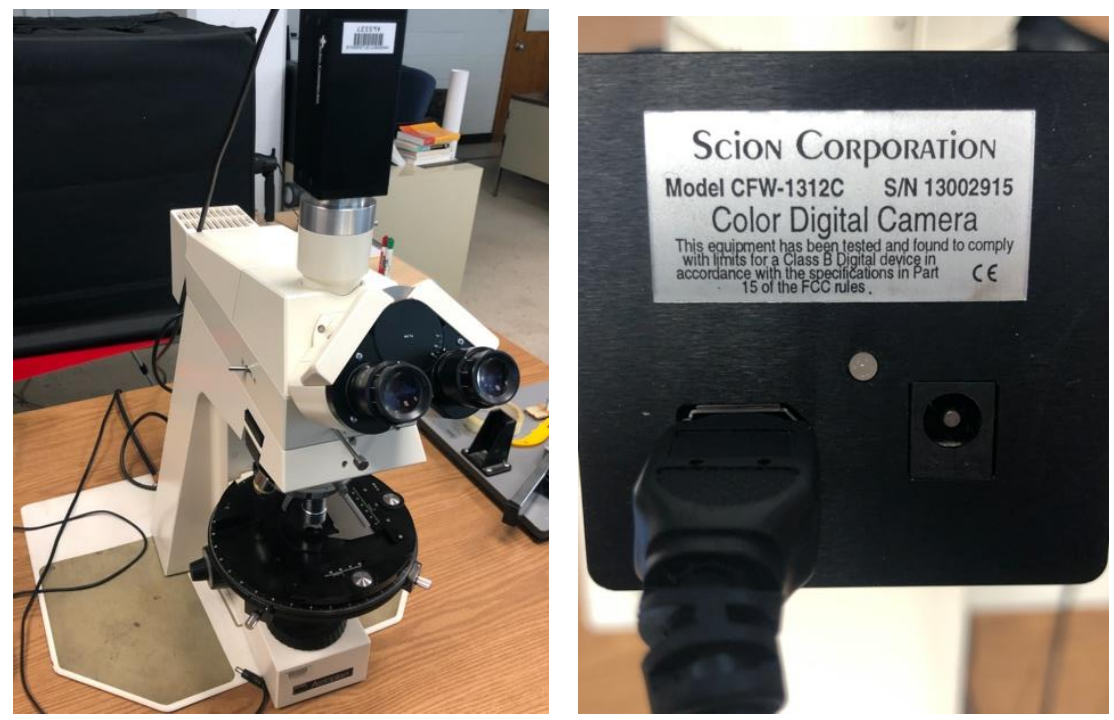

Instrumentation used for whole-thin section imaging to produce base map mosaics: Zeiss Axioplan optical microscope fitted with a Scion Corporation CFW-1312C Color Digital Camera, housed in the Department of Geography and Geosciences at the University of Louisville. 


\section{CURRICULUM VITAE}

Elliott Michael Holmes

elliott.holmes@1ouisville.edu | 502.718.3862

\section{$\underline{\text { EDUCATION }}$}

M.S., Applied Geography, Anticipated August 2020- University of Louisville, Louisville, $K Y$

- GPA: 3.98; on-going thesis research, "GIS and remote sensing approaches for analysis of microstructural data from drill core samples from the San Andreas Fault Observatory at Depth (SAFOD)" (Advisors: J. Hadizadeh, A. Gaughan, D.J. Biddle, F. Stevens, A. Farag)

B.S., Applied Geography with a Track in Environmental Analysis, 2018- University of Louisville, Louisville, $K Y$

- GPA: 3.1; thesis, "An evaluation of MSD storage basin efficiency from 1997 to 2015 in the Middle Fork and South Fork of Beargrass Creek" (Advisor: J. Hadizadeh)

\section{RESEARCH EXPERIENCE}

Graduate Research Assistant, University of Louisville August 2018 - August 2020

- Worked with research group to develop GIS-based procedures for management and spatial analyses of microstructural data from drill core samples

- Gained experience with analytical techniques including photogrammetry, optical microscopy, scanning electron (SEM) and cathodoluminescence (CL) microscopy, x-ray diffraction (XRD), and computed tomography (CT) scanning

- Applied remote sensing techniques of image classification to CL images from petrographic thin sections

- Grant information: NSF Award 1800933 (\$290,478). A microstructural study of deformation in currently-inactive fault rocks from the San Andreas Fault Observatory at Depth pertinent to aseismic creep in central California. PI/Co-PI: Jafar Hadizadeh, Andrea Gaughan. Co-I: D.J. Biddle. September 2018 - August 2021.

Senior Thesis, University of Louisville August 2017 - April 2018 
- Collaborated with research teams at the University of Louisville, the Louisville Metropolitan Sewer District (MSD), and the United States Geological Survey (USGS)

- Conducted spatial analysis of regional storm water retention basin efficiency using MSD basin locations, USGS stream discharge records, and topographical GIS data products

\section{TEACHING EXPERIENCE}

Undergraduate Teaching Assistant, Geography \& Geosciences, University of Louisville January 2018 - April 2018

- Teaching assistant for The Global Environment

- Facilitated retention of key concepts in physical geography by addressing student questions during scheduled office hours, participating in regular online discussion forums, and conducting weekly live/recorded review sessions of course material

- Attended quarterly teaching and leadership development events as part of the NSF-funded Program for Retention and Improvement in Mathematics, Engineering, and Science

\section{PRESENTATIONS}

2020 A GIS-based method for archival and visualization of microstructural data from drill core samples. Presentation at the Graduate Student Regional Research Conference. University of Louisville, Louisville, KY.

2019 Digital modelling of core billets for GIS-based microstructural analysis of SAFOD Samples. Presentation at the 2019 Annual Meeting of The American Geophysical Union (AGU). San Francisco, CA.

2018 Invited presentation. An evaluation of MSD storage basin efficiency from 1997 to 2015 in the Middle Fork and South Fork of Beargrass Creek. Presentation at the Science Week seminar series at the United States Geological Survey (USGS) Ohio/ Kentucky/ Indiana (OKI) Water Science Center. Louisville, KY.

\section{AWARDS/ SCHOLARSHIPS}

2018 Outstanding Graduate, Department of Geography \& Geosciences, University of Louisville (\$500)

2018 Graduate Research Assistantship, scholarship from NSF grant 1800933, University of Louisville (full-tuition scholarship for 2018-2020 academic years) 


\section{PROFESSIONAL SOCIETIES}

2019 - 2020 Member, The American Geophysical Union (AGU)

2018 - 2020 Member, The American Association of Geographers (AAG)

2017 - 2020 Member, The Kentucky Association of Mapping Professionals (KAMP)

\section{ADDITIONAL EXPERIENCE}

\section{The United States Geological Survey (USGS)}

Hydrologic Technician, Louisville, KY

May 2016 - August 2016

- Facilitated upkeep of Kentucky's hydrological monitoring network by conducting stream discharge measurements, calibrating and rain and stream gauges, and performing site maintenance and safety tasks

Sediment Laboratory Technician, Louisville, KY

June 2017 - July 2020

- Advanced the USGS water science mission by performing various analyses on water and sediment samples from eastern US states

- Managed sample storage, preparation, and shipping in accordance with laboratory safety and database administration protocol

- Attended regular research seminars, lab safety and analytical technique trainings, and leadership/professional development events

\section{Independent Contracting}

Image Processing Specialist, Louisville, KY

March 2020 - Present

- Sub-contractor; NASA initiative entitled "Augmenting the FIREX-AQ Program with a Rapid-Response, Low-Cost, Broad Area Dual VisLWIR Remote Sensing System", awarded to Urban Sky Theory, Inc. Involvement is in support of the "Data Recovery, Analysis \& Delivery" task, focused on the processing, stitching, and orthorectification of sub-sets of the entire captured data set in GIS-compatible formats 